\title{
Psychological Treatment of Obsessive-Compulsive Disorder in Children and Adolescents: a Meta-Analysis
}

\author{
Ana I. Rosa-Alcázar, Julio Sánchez-Meca, Ángel Rosa-Alcázar, Marina Iniesta-Sepúlveda, \\ José Olivares-Rodríguez and José L. Parada-Navas \\ Universidad de Murcia (Spain)
}

\begin{abstract}
Although several meta-analyses have investigated the efficacy of psychological treatments for pediatric obsessive-compulsive disorder (OCD), there is not yet a consensus on the most efficacious treatment components. A meta-analysis was carried out to examine the efficacy of the different treatment techniques used in the psychological interventions of pediatric OCD. An exhaustive literature search from 1983 to February 2014 enabled us to locate 46 published articles that applied some kind of cognitive-behavioral therapy (CBT). For each group the effect size was the standardized pretest-posttest mean change, and it was calculated for obsessive-compulsive symptoms and for other outcome measures. The results clearly showed large effect sizes for CBT in reducing obsessive-compulsive symptoms and, to a lesser extent, other outcome measures $\left(d_{+}=1.860 ; 95 \% \mathrm{CI}: 1.639 ; 2.081\right)$. The most promising treatments are those based on multicomponent programs comprising ERP, cognitive strategies, and relapse prevention. The analysis of other potential moderator variables and the implications for clinical practice are discussed.
\end{abstract}

Received 19 October 2013; Revised 18 September 2014; Accepted 23 September 2014

Keywords: obsessive-compulsive disorder, cognitive-behavioral therapy, childhood, adolescence, meta-analysis.

According to the DSM-V (American Psychiatric Association, 2013) obsessive-compulsive disorder (OCD) is characterized by obsessions and compulsions that interfere with a person's normal life. OCD is suffered not only by adult people, but also by children and adolescents, and its impact on the patients' lives can be severe. OCD causes considerable interference in children's activities (play, academic tasks, social life, etc.) due to the enormous amount of time lost that compulsions generate (Taylor, 2011; Valderhaug \& Ivarsson, 2005). Prevalence rates reported by some studies in the child and adolescent population have reached figures around $2 \%$, some even reaching $4 \%$ (Rapoport et al., 2000; Zohar, 1999). In addition, OCD is often associated with other psychological disorders, such as tics, attention deficit-hyperactivity disorder, or depression, which increase the degree of discomfort and complicate its treatment and prognosis (Storch, Larson et al., 2010).

In recent years, pediatric OCD has received increased attention from clinicians and researchers, leading to an improvement of assessment measures and treatments (Krebs \& Heyman, 2010). Cognitive-behavioral therapy (CBT) has been the most investigated treatment model, exposure with response prevention (ERP) being the

Correspondence concerning this article should be addressed to Julio Sánchez-Meca. Dept. of Basic Psychology \& Methodology. Faculty of Psychology Espinardo Campus. Universidad de Murcia. 30100. Murcia (Spain). Phone: +34-868884114.

E-mail: jsmeca@um.es Web site: www.um.es/metaanalysis main component. The efficacy of ERP seems to be similar whether it is applied alone or in combination with other techniques, at least in adults (Rosa-Alcázar, Sánchez-Meca, Gómez-Conesa, \& Marín-Martínez, 2008). The treatment components that most frequently accompany ERP are psychoeducation (March \& Mulle, 1998), family-based treatments with parent training (Barrett, Healy-Farrell, \& March, 2004; Freeman et al., 2008), intervention in narrative context (March \& Mulle, 1998; Wagner, 2003), and cognitive or anxiety management techniques with the use of age appropriate metaphors to facilitate cognitive restructuring (Barrett et al., 2004; March \& Mulle, 1998; Pediatric OCD Treatment Study [POTS] Team, 2004; Piacentini \& Langley, 2004).

Empirical studies conducted on pediatric OCD have examined the efficacy of treatments in different modalities. For example, there have been no relevant differences observed between individual and group CBT, with efficacy figures ranging between $61 \%$ and $65 \%$ for both modalities (Barrett et al., 2004). Similarly, intensive CBT seems to be as efficacious as CBT applied in a longer format (Franklin et al., 1998; Storch, Geffken et al., 2007). CBT has been investigated with the inclusion of certain modifications, such as telephone format (Turner, Heyman, Futh, \& Lovell, 2009), communitybased CBT (Farrell, Schlup, \& Boschen, 2010), or webcamera delivered CBT (Storch et al, 2011). However, the differential efficacy between the components of CBT has not received much attention. Only the study by Simons, Schneider, and Herpertz-Dahlmann, (2006) 
has compared the benefits of ERP and meta-cognitive therapy, finding non-significant differences.

Some studies have examined the efficacy of familybased programs, finding improvement percentages of around 25-65\% (Barrett et al., 2004; Farrell et al., 2010; Piacentini \& Langley, 2004; Scahill, Vitulano, Brenner, Lynch, \& King, 1996; Valderhaug, Larsson, Götestam, \& Piacentini, 2007; Waters, Barrett, \& March, 2001). In addition, some reviews point towards the existence of significant differences between fathers and mothers according to gender, age of children (Bögels \& Phares, 2008), and parental style dimensions (McLeod, Wood, \& Weisz, 2007). Creswell and Cartwright-Hatton (2007) indicated the convenience of family-based CBT for child anxiety when parents show high levels of this problem.

Several qualitative reviews on pediatric OCD treatment have tried to classify psychological interventions according to Evidence-Based-Treatment criteria proposed by Chambless, Baker, Baumon, Beutler, and Calhoun (1998) and Chambless and Hollon (1998). Thus, Barrett, Farrell, Pina, Peris, and Piacentini (2008) concluded that individual exposure-based CBT can be considered as a probably efficacious treatment and that family-based CBT, both in individual or group format, can be considered as a possibly efficacious treatment as well. Barrett et al. (2008) also pointed some limitations of the primary studies, such as the comorbidity and the heterogeneity and small size of the samples. Krebs and Heyman (2010) reported that in cases with refractory OCD relevant variables such as comorbidity, family factors and symptom-related characteristics must be addressed, since these may hinder the treatment efficacy. Finally, in the American Academy of Child and Adolescent Psychiatry (AACAP) Committee on Quality Issues (2012) CBT is recommended as the first choice when OCD presents mild to moderate severity, whereas selective serotonin reuptake inhibitors (SSRIs) combined with CBT are indicated for moderate to severe cases.

\section{Review of previous meta-analyses}

There have been published four meta-analyses on the efficacy of psychological interventions in pediatric OCD (Abramowitz, Whiteside, \& Deacon, 2005; Freeman et al., 2007; O'Kearney, 2007; Watson \& Rees, 2008). Abramowitz et al. (2005) identified 18 articles, published between 1983 and 2004, that included 10 ERP groups, 10 pharmacotherapy groups, and seven placebo control groups. The effect size index was the standardized pretest-posttest mean change for each group. For the obsessive-compulsive measures, a mean effect $d=1.98$ was obtained for the ERP groups and $d=0.48$ for the placebo control groups, both of them reaching statistical significance. Following Cohen's (1988) criterion to interpret the magnitude of the $d$ indices, ERP treatment exhibited a large magnitude (over 0.8), whereas the placebo control showed a medium magnitude (about 0.5). In addition, a combined effect size was calculated for the anxiety and depression measures, obtaining a mean $d=0.48$ for ERP (four groups) and $d=0.06$ for control groups (four groups), none of which were statistically significant.

Freeman et al. (2007) integrated 12 CBT groups, published between 1983 and 2005, and calculated the same effect size index as that used in Abramowitz et al. (2005) to estimate treatment efficacy in reducing obsessive-compulsive symptoms. Assuming a randomeffects model, they obtained a mean $d=1.55$, which was statistically significant. They also calculated mean effects separately for individual CBT, $d=1.77$ (seven groups), group CBT, $d=0.76$ (three groups), and family-based CBT, $d=1.88$ (two groups), concluding that individual and family-based CBT seem to be the most promising treatments of pediatric OCD.

O'Kearney (2007) recovered 19 articles, published between 1983 and 2007, five of which were comparison studies and 14 were one-group studies. For the onegroup studies, the same $d$ index defined in the two previous meta-analyses was calculated, with $d$ indices for obsessive-compulsive measures ranging between 0.78 and 3.49. Due to the large variability shown by the effect estimates, a mean effect was not calculated in the study. O'Kearney (2007) considered the effect estimates obtained from the one-group studies as overestimations of the true treatment effect due to the low internal validity of these designs. In order to correct the effect estimates, he adjusted the $d$ indices of the one-group studies by the mean $d$ index obtained with the control groups, concluding that, on average, the mean effect of CBT is around $d=1$. Due to the large number of internal validity threats of the one-group studies, Watson and Rees (2008) selected only randomized controlled studies that applied some psychological or pharmacological treatment to children and adolescents with OCD. They selected 12 articles and one unpublished paper (1985-2008) that produced 15 comparisons between a treatment group and a control group, although only five of them engaged CBT. The high methodological quality of the studies included in this meta-analysis allowed the use of an effect size index that controlled the internal validity threats. This effect size was defined as the difference between the pretest-posttest mean changes of the treatment and control groups, divided by the pooled standard deviation of the two groups in the posttest. For the five CBT comparisons, the mean effect was $d=1.45$, statistically significant and exhibiting a large magnitude following Cohen's (1988) criteria. 
In summary, the results obtained in the four metaanalyses carried out to date about the efficacy of CBT for pediatric OCD point towards ERP as the main treatment component and towards individual and family-based CBT as the most promising treatment modalities.

\section{Objectives of the study}

The previous meta-analyses have shown that CBT exhibits great efficacy in children and adolescents with $O C D$, although their effect estimates vary depending on the effect size index used. The scarce number of controlled studies that assess the efficacy of CBT on pediatric OCD led us to include one-group studies in the meta-analysis, in spite of their internal validity problems. As a consequence, assessments of the risk of bias in the effect estimates need to be addressed. The purpose of this research was to carry out a metaanalysis on the efficacy of psychological treatments in pediatric OCD to determine the current status and future directions in the field. Our meta-analysis offers some improvements to those previously published on this topic. First, one objective not addressed in the previous meta-analyses was to tentatively explore the differential efficacy of the different components that CBT can include, such as ERP, cognitive restructuring, psychoeducation, anxiety management training, problem-solving strategies, relapse prevention, behavioral experiments, etc. With this purpose, a tentative model was proposed in order to explore the most relevant treatment components on pediatric OCD with the aim to guide future experimental research on this topic. Second, in addition to obsessive-compulsive symptoms, we have examined the treatment effects on other outcome measures, such as anxiety, depression, family adaptation, functional impairment, and other measures. Only Abramowitz et al. (2005) computed a combined effect size for anxiety and depression symptoms. Third, the effect sizes were calculated in the posttest and in the follow-up, allowing us to study both the short-term and the long-term efficacy of the treatments. Fourth, efforts were made to analyze a wide range of treatment, participant, context, methodological, and extrinsic moderator variables that could account for the effect size variability.

\section{Method}

\section{Study Selection Criteria}

In order to be included in the meta-analysis, studies had to fulfill the following criteria: a) to examine the efficacy of a psychological treatment on a sample of participants younger than 19 years old with a diagnosis of OCD according to standardized diagnostic criteria (e.g., DSM or ICD) and clinician-administered structured clinical interviews (e.g., SCID, ADIS-III, ADIS-IV); b) to include at least one treatment group with pretest and posttest measures and, optionally, follow-up measures; c) the sample size in the posttest should be greater than four participants; therefore, single-case designs were excluded; d) statistical data reported in the study had to allow us to compute the effect sizes, and e) to be written in English or Spanish.

\section{Search strategy}

Several literature search procedures were used to locate the studies that could fulfill our selection criteria. First, several electronic databases were consulted: Medline, PsycINFO, PsycARTICLES, Psychology and Behavioral Sciences Collection (PBSC), ERIC, and Google Scholar, as well as the Spanish database CSIC (ISOC). The following keywords were combined, in English and Spanish, in the electronic searches: ([obsessive-compulsive] or [OCD]) and ((treatment) or (cognitive behavioral therapy) or (CBT) or ([exposure response prevention] or [ERP]) and ([pediatric] or [child*] or [adolesce*]), which should be in the title or the abstract. Second, the references of four meta-analyses cited above and six systematic reviews were consulted (Barrett et al., 2008; Himle, 2003; March, 1995; March, Franklin, Nelson, \& Foa, 2001; Turner, 2006; Wolff \& Wolff, 1991). Third, the references of the located studies were also reviewed. Finally, emails were sent to 22 experts in this area in order to locate unpublished studies. A flow chart of the literature search process is showed in Figure 1.

The search strategy produced a total of 1,105 references, finding 46 articles that fulfilled the selection criteria, all of them written in English and published between 1983 and February of 2014. Out of the 46 articles, 28 were one-group studies, 17 were comparison studies with random assignment (seven studies with a control group, ten with alternative CBT groups and medication group,) and one comparison twogroups study. The 46 articles produced a total of 62 groups: 54 groups of participants that received some kind of CBT, one group of psychodynamic therapy, and seven control groups (six nonactive groups and one pill-placebo group). In total, 1,164 participants were included in the posttest measurements $(1,051$ in the treatment groups and 113 in the control groups), with a median sample size of 15 participants. The studies came from USA (58.7\%), United Kingdom $(15.2 \%)$, Australia (10.9\%), Canada (4.3\%), Germany $(2.2 \%)$, Brazil $(2.2 \%)$, Netherlands $(2.2 \%)$, Norway $(2.2 \%)$, and Iran $(2.2 \%)$. Although we endeavored to locate unpublished studies, all those included in the meta-analysis were published papers. 


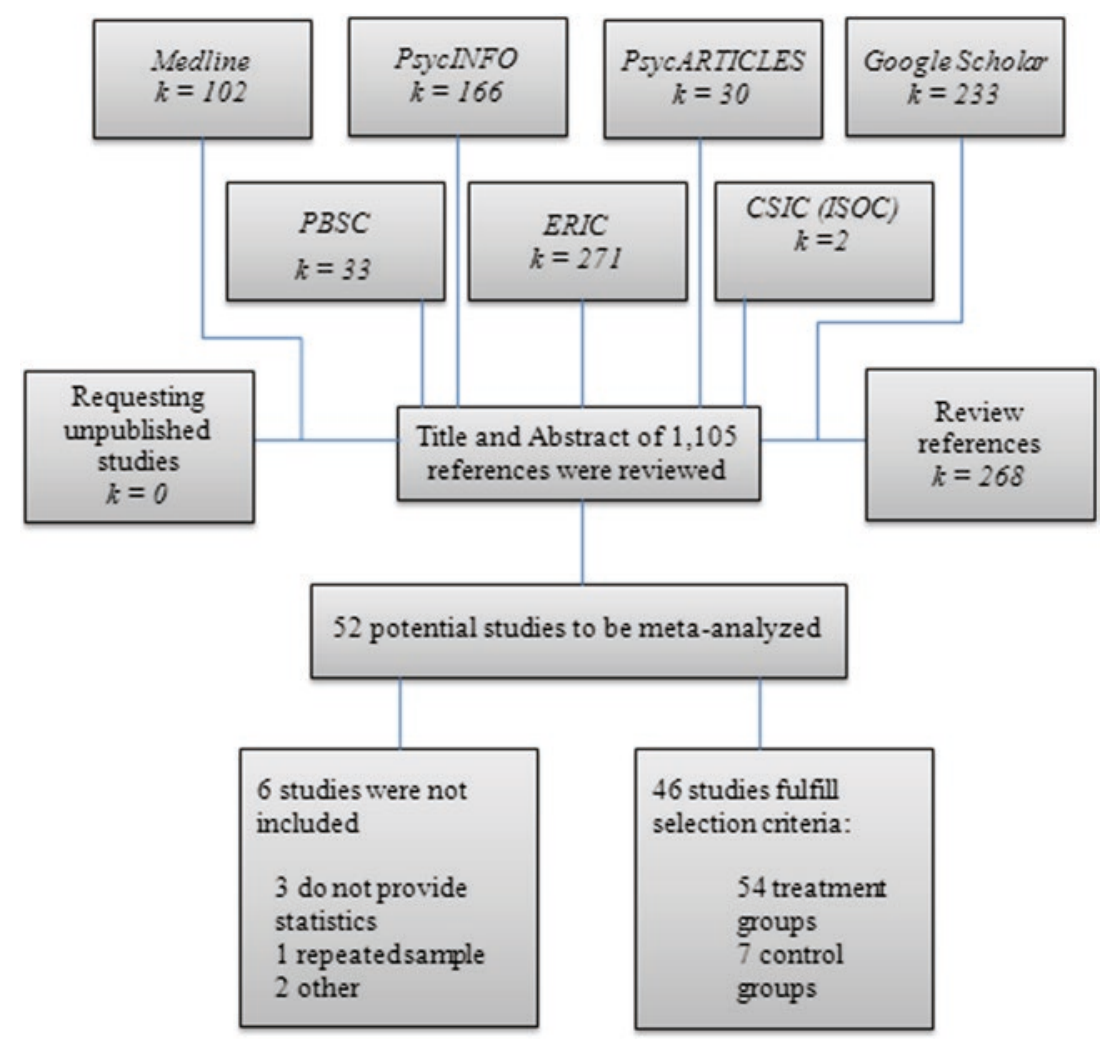

Figure 1. Flow chart of the search strategy and study selection process.

The degree of overlap, in terms of the number of articles of our meta-analysis that were already been included in each one of the previous ones was $26 \%$ with Freeman et al. (2007) and 34.8\% with O'Kearney (2007). In these two meta-analyses only psychological treatments were included. The overlap was even lower when compared our meta-analysis with other meta-analyses that also included pharmacological treatments, such as Watson and Rees (2008) with $6.5 \%$, or Abramowitz et al. (2005) with $19.6 \%$. The minor overlap between our meta-analysis and the previous ones guarantees the originality of our results.

\section{Coding of moderator variables}

In order to examine the potential influence of characteristics of the studies on the effect sizes, potential moderator variables were coded. The treatment variables coded were: a) the type of group (treatment versus control); b) the behavioral techniques applied to the participants (psychoeducation, ERP, cognitive restructuring, relapse prevention, behavioral experiments, etc.); c) the type of exposure (in vivo versus in imagination); d) the mode of applying the exposure (therapist-guided, parent-guided, self-exposure, therapist-guided with audiovisual support, parent-guided with audiovisual support, and self-exposure with audiovisual support); e) the treatment duration (number of weeks); f) the treatment intensity (number of weekly hours); g) the treatment magnitude (total number of intervention hours per participant); h) the homogeneity of the treatment (if it was similar for all subjects); i) the inclusion of homework; $j$ ) the inclusion of a follow-up program; k) the degree of parental involvement (minimal: parents only received information; moderate: parents attended some sessions, or high: parents attended almost all sessions and were trained to assist children); 1) the focus of the intervention (the OCD child or the whole family); $\mathrm{m}$ ) the mode of CBT (individual versus in group); n) the utilization of a manualized protocol; o) the therapist's training (psychologist versus psychiatrist); and p) the therapist's experience (low: graduate students with no experience; moderate: postgraduate students with experience, or high: professionals or faculty members with experience).

Several participant characteristics were also coded: a) the mean age of the sample (in years); b) the gender distribution (percentage of males); c) the mean duration of the OCD (in years); d) whether they had received any previous treatment (somebody versus nobody); and e) the presence of comorbidity $(<50 \%$ versus $\geq 50 \%$ of the sample). The methodological variables coded were: a) the diagnostic criteria (any version of DSM, ICD or others); b) the control of 
medication consumption; c) the inclusion of follow-up measures (in months); d) the attrition from pretest to posttest, and e) the methodological quality of the study (on a scale of $0-6$ points) ${ }^{1}$.

The coding process was carried out in a standardized and systematic way since a codebook and a protocol for registering the variables ${ }^{2}$ had been produced previously. To assess the reliability of the coding process, $20 \%$ of the studies were randomly selected and subjected to a double coding process by two previously trained coders. The results showed very satisfactory inter-coder reliability, with kappa coefficients ranging from 0.85 to 1 for the qualitative variables, and intra-class correlations between 0.99 and 1 for the continuous ones.

\section{Computation of effect sizes}

The type of designs used in the studies conditioned the selection of the effect size index in our meta-analysis. Only seven of the 46 articles included a control group. As a consequence, our analysis unit was the group, not the study, and the effect size index was the standardized change scores index, defined as the difference between the pretest and the posttest means divided by the pretest standard deviation: $d=c(m)\left(\bar{y}_{\mathrm{Post}}-\bar{y}_{\mathrm{Pre}}\right) / S_{\mathrm{Pre}}$, with $c(m)$ being a correction factor for small sample sizes (Hedges \& Olkin, 1985).

The $d$ index was calculated for the 55 treatment groups and for the seven control groups. To calculate effect sizes in the follow-ups, the same formula was used with the follow-up mean instead of the posttest mean. Positive values for $d$ indicated a favorable change in the group from the pretest to the posttest (or the follow-up), and vice versa.

In order to control some of the validity threats of this effect size index, we computed the $d$ index for both treatment and control groups. In this way, the difference between the mean $d$ indices for the treatment and the control groups can offer a more realistic estimate of the true effect.

Separate effect sizes were calculated for obsessivecompulsive symptoms, anxiety, depression, family adaptation, functional impairment, and other outcome measures. In order to measure obsession and compulsion symptoms, the most frequent clinician instruments were the Children's Yale-Brown Obsessive-Compulsive

\footnotetext{
${ }^{1}$ The items that composed the methodological quality scale were: (1) random versus non-random assignment of participants to the groups; (2) the internal validity of the design (active control group, non active control group or no control group); (3) the sample size in the posttest; (4) the attrition in the treatment group; (5) the use of intent-to-treat analysis; and (6) the use of blinded assessors in measuring the outcomes. Each one was rated from 0 to 1 .

${ }^{2}$ Both documents can be obtained from the corresponding author upon request.
}

Scale (CY-BOCS; Scahill et al., 1997) and the ObsessiveCompulsive Subscale of National Institute of Mental Health Diagnostic Interview Schedule for Children (NIMH-OCS; Shaffer, Fisher, Lucas, Dulcan, \& SchwabStone, 2000). Self-reports for measuring obsession and compulsion symptoms were the Leyton Obsessional Inventory - Child Version (LOI-CV; Berg, Rapoport, \& Flament, 1986) and the Children's Obsessional Compulsive Inventory (CHOCI; Shafran et al., 2003). General anxiety was measured mainly by means of the Multidimensional Anxiety Scale for Children (MASC; March, Parker, Sullivan, Stallings, \& Conners, 1997) and the Revised Children's Manifest Anxiety Scale (RCMAS; Reynolds \& Richmond, 1978). Depression symptoms were measured with the Children's Depression Inventory (CDI; Kovacs, 1992), the Children's Depression Rating Scale-Revised (CDRS-R; Poznanski, Freeman, \& Mokros, 1985), and the Hamilton Rating Scale for Depression (HAM-D; Hamilton, 1960). Functional impairment was measured basically with the Child Obsessive Compulsive Impact Scale-Child/Parent for functional impairment (COISC/P; Piacentini \& Jaffer, 1999) and the Clinical Global Impression-Severity/Improvement (CGI-S/I; Guy, 1976; National Institute of Mental Health, 1985). Family adaptation was measured with the McMaster Family Assessment Device (FAD; Epstein, Balwin, \& Bishop, 1983). Included in the category 'other outcomes' were such tests as the Global Assessment of Functioning Scale (GAF; Startup, Jackson, \& Bendix, 2002) and the Children's Global Assessment Scale (C-GAS; Shaffer et al., 1983).

For the assessment of the reliability of the effect size calculations, the same random sample of studies used in the coding reliability study was subjected to a double process of effect size calculations, obtaining excellent inter-coder reliability, with intra-class correlations of over 0.99 .

\section{Statistical Analysis}

Separate meta-analyses were carried out with the effect sizes for each outcome measure. In order to accommodate the variability exhibited by the effect sizes, random-effects models were assumed (Borenstein, Hedges, Higgins, \& Rothstein, 2009). To assess the heterogeneity of the effect sizes, the $Q$ statistic and the $I^{2}$ index were calculated. For each outcome measure, a weighted mean effect size with its confidence interval was calculated separately for the treatment groups and for the control groups (Sánchez-Meca \& Marín-Martínez, 2008). Given that our meta-analysis did not include any unpublished papers, an analysis of publication bias was carried out. The influence of moderator variables on the effect sizes was carried 
out by assuming a mixed-effects model. Both randomand mixed-effects models applied in this meta-analysis implied to weight each study as a function of its precision, and the precision is mainly a function of the sample size: the larger the sample size, the larger the precision of the effect size. The statistical analyses were carried out with the SPSS macros developed by David B. Wilson ${ }^{3}$, with the exception of the forest plot, which was constructed with the program RevMan 5.3.

\section{Results}

\section{Distribution of effect sizes}

A table with the main moderator variables and effect sizes for each group is presented in the Appendix. For each outcome measure a separate meta-analysis was carried out in order to estimate the mean effect size and its 95\% confidence interval. Table 1 presents the results obtained separately for the treatment groups and for the control groups in each outcome measure, and Figure 2 presents a forest plot for the obsessivecompulsive symptoms.

Focusing on the most important outcome measure in the treatment of pediatric OCD, the obsessivecompulsive symptoms, the results showed a statistically significant mean effect for the 55 treatment groups $\left(d_{+}=1.860\right)$, whereas the mean effect for the seven control groups did not reach statistical significance $\left(d_{+}=0.232\right)$. Furthermore, an ANOVA applied to compare the two mean effects showed statistically significant differences and a large proportion of variance explained of $0.48, Q_{\mathrm{B}}(1)=32.411, p \leq .0001$. Due to its low internal validity, the mean $d$ index obtained for the treatment groups may be overestimating the true effect. A reasonable strategy for controlling the testing effects suffered by these $d$ indices is to define an adjusted mean effect, $d_{\mathrm{adj}}$, as the difference between the mean effect of the treatment groups, $d_{\mathrm{T}}$, and the mean effect of the control groups, $d_{\mathrm{C}}: d_{\mathrm{adj}}=d_{\mathrm{T}}-d_{\mathrm{C}}$. Thus, for the global measures of obsessive-compulsive symptoms an estimate of the true treatment effect was $d_{\text {adj }}=1.860-0.232=1.628$, an effect estimate that can still be considered of large magnitude (Cohen, 1988).

Regarding obsessive-compulsive symptoms, Table 1 also presents separately the mean effect obtained for clinician-administered instruments and for self-reports. One noteworthy result is the large mean effect size obtained for clinician-administered instruments $\left(d_{+}=2.022\right)$ in comparison to that of self-reports $\left(d_{+}=0.816\right)$, although in both cases the mean effect was statistically significant, as well as their corresponding

${ }^{3}$ The SPSS macros can be obtained from David B. Wilson's web site: http:/ / mason.gmu.edu/ dwilsonb/ma.html. adjusted mean effect sizes (clinician-administered: $d_{\text {adj }}=2.022-0.358=1.664$; self-reports: $d_{\text {adj }}=0.816$ $-0.073=0.743)$.

Effect sizes for the 23 treatment groups that measured anxiety symptoms showed a medium, statistically significant mean effect for the treatment groups $\left(d_{+}=0.603\right)$, whereas the four control groups that reported anxiety measures obtained a positive but non statistically significant mean effect $\left(d_{+}=0.133\right)$. When the two mean effects were statistically compared, the difference between them led to a statistically significant difference, $Q_{\mathrm{B}}(1)=4.158, p=.041 ; R^{2}=.139$. The difference between the two mean effects gave an adjusted effect size of a medium magnitude: $d_{\mathrm{adj}}=0.603$ $-0.133=0.470$.

With depression measures the results were slightly less favorable than with the anxiety: the treatment groups obtained a mean effect $d_{+}=0.448$, but larger than the one obtained with the control groups $\left(d_{+}=0.129\right)$, a difference that was statistically significant, $Q_{\mathrm{B}}(1)=4.445$, $p=.035 ; R^{2}=.889$. The adjusted mean effect was of low-medium magnitude: $d_{\mathrm{adj}}=0.448-0.129=0.319$.

For family adaptation outcomes, the treatment groups obtained a mean effect of $d_{+}=0.494$, whereas the mean effect for the control groups was practically null $\left(d_{+}=0.025\right)$. The difference between these two mean effects was not statistically significant, $Q_{\mathrm{B}}(1)=1.445, p=.229 ; R^{2}=.048$. However, the adjusted mean effect size was of medium magnitude: $d_{\mathrm{adj}}=0.494$ $-0.025=0.469$.

For other outcome measures, the treatment groups exhibited a mean effect of $d_{+}=1.466$, whereas the mean effect of the control groups was $d_{+}=0.083$. The statistical comparison between these two mean effects reached statistical significance, $Q_{\mathrm{B}}(1)=5.520, p=.019$; $R^{2}=.281$, and the adjusted mean effect size was of a large magnitude: $d_{\mathrm{adj}}=1.466-0.083=1.383$.

Finally, for functional impairment measures, the mean effect for the 16 groups that reported data about this type of outcomes was statistically significant and of a large magnitude $\left(d_{+}=0.743\right)$. In this case, it was not possible to calculate an adjusted mean effect due to the absence of data for control groups.

Since all the studies included in the meta-analysis were published papers, we calculated the fail-safe $N$, which involved calculating the number of unpublished studies averaging a null effect that must exist in order for the mean effect obtained in a metaanalysis to become zero (Becker, 2005). In our metaanalysis this safe number was $N_{\mathrm{fs}}=5 k+10=5 \times 55+10$ $=285$. Taking the adjusted mean effect for obsessivecompulsive measures, $d_{\mathrm{adj}}=1.628$, the tolerance number for null results was equal to $N=895$. As $N>N_{\mathrm{fs}}$ we can discard publication bias as a threat for our meta-analysis. 


\section{Analysis of Moderator Variables}

As Table 1 shows, effect sizes for the treatment groups exhibited large heterogeneity in obsessivecompulsive symptoms, general anxiety, family adaptation, and other outcome measures. Consequently, an analysis of the characteristics of the studies that could affect the effect size variability was carried out. For this purpose, however, we focused only on obsessive-compulsive measures, as these are the main symptoms that the treatments intend to reduce. Out of the 55 treatment groups, 54 applied some type of CBT with only one group applying a non-cognitivebehavioral treatment (Rezvan et al., 2013). Thus, the non-CBT study was excluded from the analyses of moderator variables, due to its scarce representativeness. Therefore, the analyses of moderator variables were based on the 54 groups that applied CBT.

\section{(A)Treatment Characteristics}

One of the main objectives of this meta-analysis was to examine the differential effects of the different treatment techniques included in CBT. The 54 CBT groups included psychoeducation, 47 groups applied ERP, 44 groups cognitive restructuring, 44 groups relapse prevention, six groups behavioral experiments, eight groups problem solving, and three groups biofeedback techniques.

The various techniques found in the cognitivebehavioral interventions were not mutually exclusive categories. Therefore, the only possible analytical strategy was to apply a multiple meta-regression analysis, taking the $d$ index for obsessive-compulsive measures as the dependent variable, and the predictors were a set of dummy variables $(0$, absent; 1 , present) representing the different techniques found in the studies: ERP, cognitive restructuring, relapse prevention, behavioral experiments, and problem solving. Biofeedback techniques were excluded from the analysis because of their limited use, and psychoeducation was also excluded because all treatment groups included it. The seven control groups were included in the analysis with zero values in all predictors. The full model reached the statistical significance with a large proportion of variance explained of $58.7 \%, Q_{R}(5)=45.171, p<.0001$. With the exception of problem solving, the remaining techniques obtained positive partial regression coefficients, but only relapse prevention reached statistical significance once the influence of the remaining treatment techniques was controlled $(p=.002)$.

Table 2 shows the ANOVAs carried out to analyze the influence of other characteristics related with the treatments. One of the most relevant treatment characteristics in pediatric OCD is the degree of parental involvement in the therapeutic process. In our metaanalysis, the parental involvement level was coded as low (parents only received information from the therapist about the therapeutic progress of the child), moderate (parents attended several treatment sessions), and high (parents were trained as co-therapists to develop the treatment techniques at home). As Table 2 shows, parental involvement had a positive, statistically significant association with the effect size $(p=.002)$, exhibiting a large percentage of variance explained of $34 \%$. Another variable that had a statistically significant result was the treatment protocol used $(p=.010)$ with $31 \%$ of variance explained. The most effective manualized protocols were those of Lewin, Storch, Adkins, Murphy, and Geffken (2005) and the FOCUS protocol (Barrett et al., 2004), with mean effects of

Table 1. Results for the effect sizes as a function of the outcome measure for the treatment and control groups

\begin{tabular}{|c|c|c|c|c|c|c|c|c|c|c|c|c|}
\hline \multirow[b]{3}{*}{ Outcome measure } & \multicolumn{6}{|c|}{ Treatment Groups } & \multicolumn{6}{|c|}{ Control Groups } \\
\hline & \multirow[b]{2}{*}{$k$} & \multirow[b]{2}{*}{$Q$} & \multirow[b]{2}{*}{$I^{2}$} & \multirow[b]{2}{*}{$d_{+}$} & \multicolumn{2}{|c|}{ 95\% C.I. } & \multirow[b]{2}{*}{$k$} & \multirow[b]{2}{*}{$Q$} & \multirow[b]{2}{*}{$I^{2}$} & \multirow[b]{2}{*}{$d_{+}$} & \multicolumn{2}{|c|}{ 95\% C.I. } \\
\hline & & & & & $d_{1}$ & $d_{\mathrm{u}}$ & & & & & $d_{1}$ & $d_{\mathrm{u}}$ \\
\hline \multicolumn{13}{|l|}{ Obsessions/compulsions: } \\
\hline Global & 55 & $198.581^{* * *}$ & 72.8 & 1.860 & 1.639 & 2.081 & 7 & 12.438 & 51.8 & 0.232 & -0.283 & 0.747 \\
\hline Clinicians & 55 & $199.794^{* * *}$ & 73.0 & 2.022 & 1.787 & 2.257 & 7 & $17.468^{* *}$ & 65.6 & 0.358 & -0.189 & 0.905 \\
\hline Self-reports & 13 & 15.129 & 20.7 & 0.816 & 0.631 & 1.000 & 3 & 1.563 & 0 & 0.073 & -0.282 & 0.427 \\
\hline General Anxiety & 23 & $56.029^{* * *}$ & 60.7 & 0.603 & 0.426 & 0.781 & 4 & 1.299 & 0 & 0.133 & -0.283 & 0.549 \\
\hline Depression & 24 & 25.426 & 9.5 & 0.448 & 0.339 & 0.556 & 4 & 0.994 & 0 & 0.129 & -0.147 & 0.405 \\
\hline Family adaptation & 11 & $36.852^{* * *}$ & 72.9 & 0.494 & 0.190 & 0.798 & 2 & 1.840 & 45.6 & 0.025 & -0.677 & 0.727 \\
\hline Functional impairment & 16 & 21.964 & 31.7 & 0.743 & 0.578 & 0.909 & - & - & - & - & - & - \\
\hline Other result measures & 20 & $90.867^{* * *}$ & 79.1 & 1.466 & 1.081 & 1.851 & 2 & 3.299 & 69.7 & 0.083 & -1.005 & 1.171 \\
\hline
\end{tabular}

Note: ${ }^{*} p<.05 .{ }^{* *} p<.01 .{ }^{* *} p<.001 .95 \%$ C.I.: $95 \%$ confidence interval. $k$ : number of studies. Q: heterogeneity statistic. $I^{2}$ : heterogeneity index $(\%) . d_{+}$: mean effect size. $d_{1}$ and $d_{\mathrm{u}}$ : lower and upper confidence limits. 


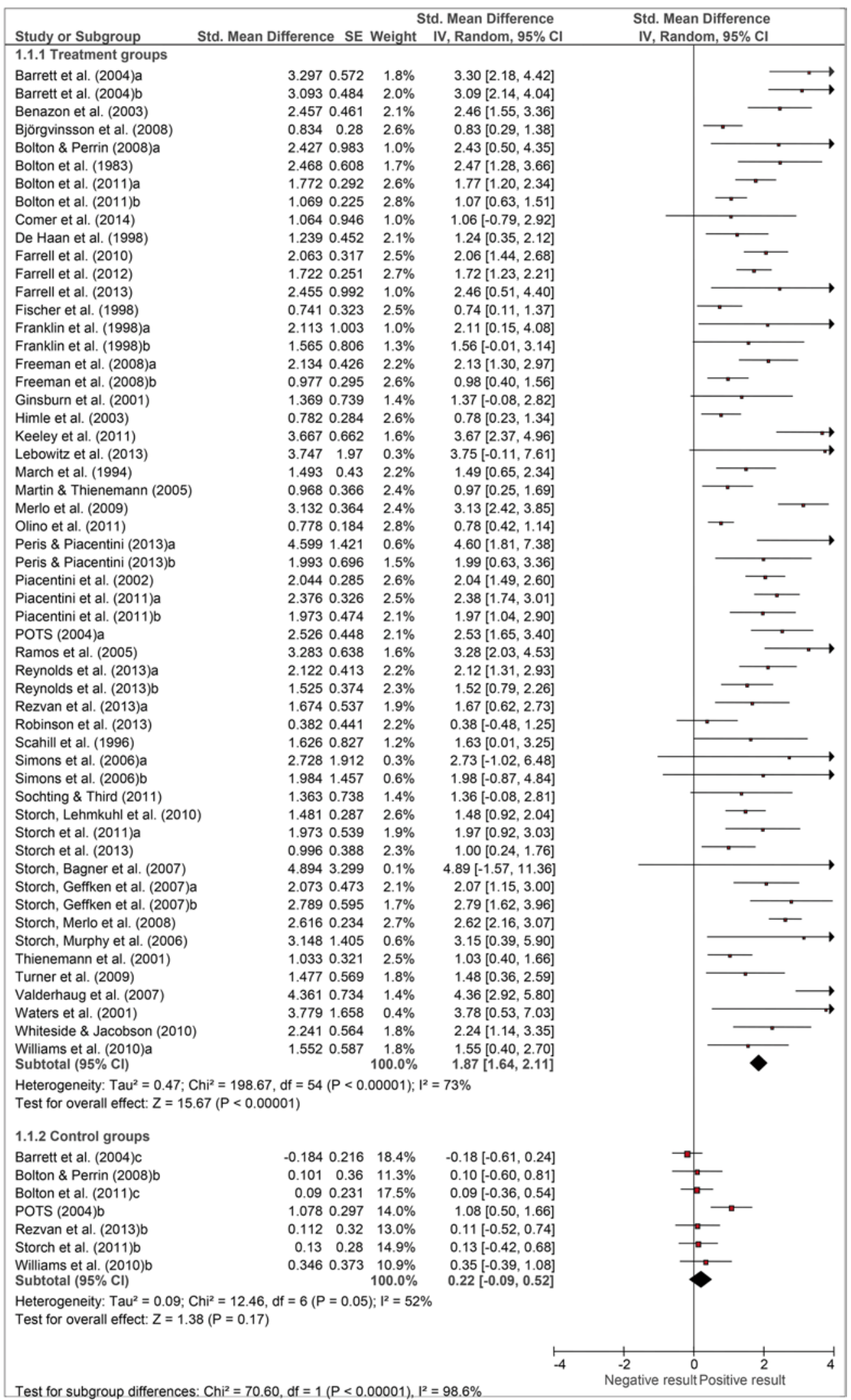

Figure 2. Forest plot of the effect size for the obsessive-compulsive symptoms classified a as function of the treatment groups and the control groups. $T a u^{2}=$ estimate of the between-studies variance. $C h i^{2}=$ heterogeneity $Q$ test. $d f=$ degrees of freedom of the $Q$ test. $Z=$ statistical test for contrasting the mean effect size. 
Table 2. Results of the ANOVAs for the influence of qualitative variables related with the treatment implementation on the effect sizes for obsessive-compulsive symptoms

$95 \%$ C. I.

\begin{tabular}{|c|c|c|c|c|c|}
\hline & & & & & \\
\hline Moderator variable & $k$ & $d_{+}$ & $d l$ & $d \mathrm{u}$ & ANOVA results \\
\hline Treatment homogeneity: & & & & & $Q_{\mathrm{B}}(1)=0.374, p=.541$ \\
\hline Homogeneous & 49 & 1.851 & 1.606 & 2.096 & $R^{2}=0.052$ \\
\hline Non-homogeneous & 5 & 2.106 & 1.327 & 2.884 & $Q_{W}(52)=184.251, p \leq .0001$ \\
\hline Follow-up program? & & & & & $Q_{\mathrm{B}}(1)=3.639, p=.056$ \\
\hline Yes & 11 & 2.391 & 1.829 & 2.953 & $R^{2}=0.002$ \\
\hline No & 34 & 1.772 & 1.473 & 2.070 & $Q_{W}(43)=138.245, p \leq .0001$ \\
\hline Parental involvement: & & & & & $Q_{\mathrm{B}}(2)=12.134, p=.002$ \\
\hline Low & 7 & 1.451 & 0.815 & 2.087 & $R^{2}=0.340$ \\
\hline Moderate & 22 & 1.540 & 1.233 & 1.847 & $Q_{W}(51)=141.824, p \leq .0001$ \\
\hline High & 25 & 2.264 & 1.950 & 2.577 & \\
\hline Focus of the treatment: & & & & & $Q_{\mathrm{B}}(1)=1.274, p=.259$ \\
\hline OCD child & 30 & 1.756 & 1.435 & 2.078 & $R^{2}=0.0$ \\
\hline Family & 24 & 2.035 & 1.674 & 2.395 & $Q_{W}(52)=195.419, p \leq .0001$ \\
\hline Mode of CBT: & & & & & $Q_{\mathrm{B}}(2)=1.787, p=.409$ \\
\hline Group & 12 & 1.781 & 1.306 & 2.256 & $R^{2}=0.080$ \\
\hline Individual & 34 & 2.017 & 1.703 & 2.331 & $Q_{W}(48)=163.995, p \leq .0001$ \\
\hline Mixed & 5 & 1.517 & 0.772 & 2.262 & \\
\hline Treatment protocol? & & & & & $Q_{\mathrm{B}}(1)=0.0004, p=.985$ \\
\hline Yes & 45 & 1.862 & 1.605 & 2.119 & $R^{2}=0.0$ \\
\hline No & 5 & 1.871 & 0.981 & 2.761 & $Q_{W}(48)=192.983, p \leq .0001$ \\
\hline Treatment protocol: & & & & & $Q_{\mathrm{B}}(9)=21.630, p=.010$ \\
\hline Salkowskis & 2 & 1.407 & 0.481 & 2.333 & $R^{2}=0.310$ \\
\hline March \& Mulle (1998) & 20 & 1.671 & 1.333 & 2.009 & $Q_{W}(33)=105.653, p \leq .0001$ \\
\hline Barrett et al. (2004) & 2 & 3.188 & 2.065 & 4.311 & \\
\hline Wagner (Up and ...) & 1 & 0.778 & -0.482 & 2.038 & \\
\hline Lebowitz (Space) & 1 & 3.747 & -0.298 & 7.792 & \\
\hline Diresley & 3 & 1.360 & 0.523 & 2.197 & \\
\hline Lewin et al.(2005) & 3 & 3.198 & 1.951 & 4.445 & \\
\hline Piacentini et al. (2002) & 4 & 2.530 & 1.760 & 3.300 & \\
\hline Simons et al. (2006) & 1 & 2.728 & -1.209 & 6.665 & \\
\hline Mixed & 6 & 2.357 & 1.594 & 3.119 & \\
\hline Therapist's training: & & & & & $Q_{\mathrm{B}}(2)=2.014, p=.365$ \\
\hline Psychologist & 37 & 1.925 & 1.646 & 2.204 & $R^{2}=0.006$ \\
\hline Psychiatrist & 4 & 1.608 & 0.508 & 2.865 & $Q_{W}(42)=154.579, p \leq .0001$ \\
\hline Both & 4 & 1.360 & 0.589 & 2.131 & \\
\hline Therapist training level: & & & & & $Q_{\mathrm{B}}(3)=7.227, p=.065$ \\
\hline High & 25 & 1.776 & 1.454 & 2.098 & $R^{2}=0.118$ \\
\hline Moderate & 10 & 2.047 & 1.547 & 2.547 & $Q_{W}(36)=101.566, p \leq .0001$ \\
\hline Low & 2 & 3.187 & 2.078 & 4.297 & \\
\hline Mixed & 3 & 2.515 & 1.507 & 3.522 & \\
\hline
\end{tabular}

Note: $k$ : number of studies. $d_{+}$: mean effect size for each category. $95 \%$ C.I.: $95 \%$ confidence interval for $d_{+} . d_{l}$ and $d_{u}$ : lower and upper confidence limits around $d_{+}$. $Q_{B}$ : between-categories statistic. $Q_{W}$ : within-categories statistic. $R^{2}$ : proportion of variance explained.

3.198 and 3.188, respectively. Although Lebowitz et al. (2013) obtained a large effect size $(d=3.747)$, it was based in only one study with a very small sample size ( $n=6$ participants) and, in fact, this effect was not statistically significant. Other protocols with very good results were those of Simons et al. $\left(2006 ; d_{+}=2.728\right)$ and Piacentini et al. $\left(2002 ; d_{+}=2.530\right)$. The training level of the therapist showed a negative, marginally significant relationship with the effects sizes $(p=.065)$, with $11.8 \%$ percentage of variance explained. The inclusion of a follow-up program after the treatment seemed to positively affect treatment efficacy, although the difference between the mean effects for studies with $\left(d_{+}=2.391\right)$ and without $\left(d_{+}=1.772\right)$ follow-up 
programs only reached a marginally statistically significant difference $(p=.056)$. The remaining moderator variables in Table 2 did not have a significant relation with the effect sizes.

Table 3 presents the results of simple meta-regressions applied on continuous moderator variables. As Table 3 shows, the median duration of the treatments was 12 weeks, with an intensity of 1.5 hours a week, and a total magnitude of about 15.5 hours. Simple metaregression analyses with each of these three moderator variables revealed non-statistically significant relationships with the effect sizes.

\section{(B)Participant characteristics}

Two qualitative participant characteristics were analyzed: whether the participants had received previous treatments for OCD $(\geq 50 \%$ of the sample versus $<50 \%$ in the sample) and the presence of comorbidity in the participants $(\geq 50 \%$ of the sample with comorbidity versus $<50 \%$ in the sample). As Table 4 shows, the results of the ANOVAs applied on these moderator variables were not statistically significant. Table 3 presents three other (continuous) variables related to the participants: the mean age (median $=13$ years), the percentage of males (median $=53.8 \%$ ), and the years suffering from OCD (median $=3.1$ years). None of these characteristics presented a significant relationship with the effect sizes.

\section{(C)Methodological characteristics}

The analysis of the influence of methodological variables on the effect sizes has a central role in meta-analysis, since it allows us to discover any deficiencies in the method that might lead to biased estimates of the true treatment effect. Surprisingly, in this case, none of the methodological characteristics analyzed reached

Table 3. Results of the simple meta-regressions of the continuous variables on the effect sizes for obsessive-compulsive measures

\begin{tabular}{|c|c|c|c|c|c|c|c|c|}
\hline Cluster/moderator variable & $k$ & Min. & Max. & Mdn & $b_{\mathrm{j}}$ & $Q_{\mathrm{R}}$ & $Q_{\mathrm{E}}$ & $R^{2}$ \\
\hline \multicolumn{9}{|l|}{ Treatment characteristics: } \\
\hline Treatment duration & 53 & 0.7 & 16 & 12 & 0.016 & 0.215 & $192.567^{* * *}$ & 0.0 \\
\hline Treatment intensity & 40 & 0.8 & 8.6 & 1.5 & -0.030 & 0.230 & $151.471^{* * *}$ & 0.027 \\
\hline Treatment magnitude & 40 & 7.7 & 28 & 15.5 & -0.0004 & 0.0002 & $164.841^{* * *}$ & 0.0 \\
\hline \multicolumn{9}{|l|}{ Participant characteristics: } \\
\hline Mean age & 54 & 6 & 15.5 & 13 & -0.039 & 0.448 & $196.141^{* * *}$ & 0.0 \\
\hline Gender & 52 & 31 & 80 & 53.8 & 0.007 & 0.357 & $195.648^{* * *}$ & 0.0 \\
\hline OCD history & 23 & 0.8 & 8 & 3.1 & -0.025 & 0.047 & $62.610^{* * *}$ & 0.0 \\
\hline \multicolumn{9}{|l|}{ Methodological characteristics: } \\
\hline Attrition in the posttest & 54 & 0 & 0.3 & 0 & 1.288 & 0.760 & $193.682^{* * *}$ & 0.0 \\
\hline Methodological quality & 54 & 0.7 & 5.9 & 3 & 0.092 & 0.842 & $193.753^{* * *}$ & 0.0 \\
\hline
\end{tabular}

Note: $k=$ number of studies. Mdn : median. $b_{\mathrm{j}}=$ regression coefficient. $Q_{\mathrm{R}}=$ statistic for testing the significance of the moderator variable. $Q_{\mathrm{E}}=$ statistic for assessing the model misspecification. $R^{2}=$ proportion of variance explained. ${ }^{* *} p<.01$. $* * * p<.001$.

Table 4. Results of the ANOVAs for the influence of qualitative variables related with the samples of participants on the effect sizes for obsessive-compulsive symptoms

$95 \%$ C. I.

\begin{tabular}{|c|c|c|c|c|c|}
\hline \multirow[b]{2}{*}{ Moderator variable } & \multirow[b]{2}{*}{$k$} & \multirow[b]{2}{*}{$d_{+}$} & & \multirow[b]{2}{*}{ ANOVA results } \\
\hline & & & $d l$ & $d \mathbf{u}$ & \\
\hline Previous treatment: & & & & & $Q_{\mathrm{B}}(1)=2.396, p=.122$ \\
\hline$\geq 50 \%$ in the sample & 31 & 1.716 & 1.412 & 2.021 & $R^{2}=0.017$ \\
\hline$<50 \%$ in the sample & 18 & 2.110 & 1.715 & 2.506 & $Q_{W}(47)=176.697, p \leq .0001$ \\
\hline Presence of comorbidity: & & & & & $Q_{\mathrm{B}}(1)=0.230, p=.631$ \\
\hline$\geq 50 \%$ in the sample & 43 & 1.836 & 1.583 & 2.088 & $R^{2}=0.0$ \\
\hline$<50 \%$ in the sample & 7 & 2.013 & 1.333 & 2.693 & $Q_{\mathrm{W}}(48)=157.274, p \leq .0001$ \\
\hline
\end{tabular}

Note: $k=$ number of studies. $d_{+}=$mean effect size for each category. 95\% C.I. $=95 \%$ confidence interval for $d_{+} . d_{l}$ and $d_{u}=$ lower and upper confidence limits around $d_{+}$. $Q_{B}=$ between-categories statistic. $Q_{W}=$ within-categories statistic. $R^{2}=$ proportion of variance explained. 
a significant result (random allocation, sample size, use of intent-to-treat analysis, use of blinded assessors, control of medication consumption, etc). However, it is worth highlighting some results. As may be expected, when the researchers used intent-to-treat analyses the mean effect $\left(d_{+}=1.807\right)$ was slightly lower than when a completers analysis was carried out $\left(d_{+}=2.361\right)$. On the other hand, an unexpected result was to find a larger mean effect when using blinded assessors $\left(d_{+}=2.146\right)$ than when they were not used $\left(d_{+}=1.749\right)$. However, this result is explained by the confounding between the variables 'blinded assessors' and 'type of measure' (self-reports vs. clinician assessments). Most of the studies included in the category 'no blinded assessors' used self-report measures and, as mentioned above, self-reports systematically showed lower effect sizes than clinician measures.

Two continuous methodological variables were also analyzed: attrition in the posttest and methodological quality, neither of which reaching a statistically significant relationship with the effect sizes (see Table 3).

\section{A Predictive Model}

The analyses of the moderator variables revealed that some characteristics of the studies were influencing the magnitude of the treatment effects on obsessivecompulsive symptoms. However, the specification tests ( $Q_{\mathrm{W}}$ for ANOVAs and $Q_{\mathrm{E}}$ for meta-regressions) revealed that none of the models was correctly specified. In order to propose a subset of studies characteristics that could explain a large quantity of the variance, a multiple meta-regression analysis was applied on the effect sizes for obsessive-compulsive symptoms as the dependent variable. The predictors in the model were selected both on a conceptual and a statistical basis. Thus, the different treatment techniques applied in the groups were included in the model, as one of our main objectives was to assess the differential efficacy of the techniques used in CBT. In addition, the parental involvement in the treatment was also included, as it exhibited a statistically significant relationship with the effect size and is a very relevant conceptual characteristic of the treatments. Therefore, the metaregression model included two clusters of predictor variables: a) a cluster of parental involvement coded as two dummy variables ( 0 , absent; 1 , present) for the categories 'high involvement' and 'moderate involvement'; and b) a cluster of treatment techniques with five dichotomous predictors ( 0 , absent; 1 , present) for the techniques ERP, cognitive restructuring, relapse prevention, behavioral experiments, and problem solving. The 54 treatment effect sizes and the seven control ones were included in the multiple meta-regression model, with the control groups being coded as zero in all of the predictor variables.

Table 5 presents the results of the multiple metaregression. The cluster of parental involvement reached a statistically significant result $(p \leq .001)$, with $56.7 \%$ of variance explained. The cluster of treatment techniques also showed a statistically significant result $(p<.001)$, with a percentage of variance explained of $58.7 \%$. When both clusters were introduced in the meta-regression model, the full model reached statistical significance $(p<.001)$ and its percentage of

Table 5. Results of the multiple meta-regression applied on the effect sizes for obsessive-compulsive symptoms

\begin{tabular}{lcccc}
\hline Predictors & \multicolumn{1}{l}{$b_{\mathrm{j}}$} & $\mathrm{Z}$ & $p$ & Model fit \\
\hline Constant & 0.341 & 1.713 & .087 & $Q_{\mathrm{R}}(7)=67.225, p \leq .001$ \\
Parent involvement (high) & 1.123 & 3.454 & .0006 & $R^{2}=0.414$ \\
Parent involvement (moderate) & 0.603 & 2.151 & .031 & $Q_{\mathrm{E}}(53)=127.245, p \leq .001$ \\
ERP & -0.069 & -0.174 & .862 & .289 \\
Cognitive restructuring & 0.330 & 1.060 & .006 & .371 \\
Relapse prevention & 0.715 & 2.768 & .020 & $\Delta R^{2}$ \\
Behavioral experiments & 0.415 & 0.896 & $\Delta Q_{\mathrm{R}}($ df $)$ & - \\
Problem solving & -0.808 & -2.327 & - & 0.102 \\
\hline Model & $Q_{\mathrm{R}}(d f)$ & $R^{2}$ & & \\
\hline Full model & $67.225^{* * *}(7)$ & 0.689 & $22.054^{* * *}(2)$ & 0.122 \\
Parent involvement cluster & $39.520^{* * *}(2)$ & 0.567 & $27.705^{* * *}(5)$ & \\
Treatment techniques cluster & $45.171^{* * *}(5)$ & 0.587 & & \\
\hline
\end{tabular}

Note: ${ }^{*} p<.05 .{ }^{* *} p<.01 .{ }^{* *} p<.001 . b_{\mathrm{j}}$ partial regression coefficient. $Z=$ statistic for testing the significance of $b_{\mathrm{j}}$. $Q_{\mathrm{R}}=$ statistic for assessing the significance of the meta-regression model. $Q_{\mathrm{E}}=$ statistic for assessing the model misspecification. $R^{2}=$ proportion of variance explained. $d f=$ degrees of freedom. $\Delta Q_{\mathrm{R}}$ and $\Delta R^{2}=$ increase in the $Q_{\mathrm{R}}$ statistic and in $R^{2}$, respectively, as a consequence of including in the model the cluster once the other cluster had already been introduced. 
variance explained reached $68.9 \%$. Out of the seven predictors included in the model, only four exhibited a statistically significant relationship with the effect sizes: the categories 'high parental involvement' $(p=.0006)$ and 'moderate parental involvement' $(p=.031)$, and the techniques 'relapse prevention' $(p=.006)$ 'solving problems' ( $p=.020)$. With the exception of 'solving problems', the remaining significant predictors exhibited positive partial regression coefficients, indicating the benefits of including them in the treatments.

Table 5 also shows the increases in statistical significance and in the proportion of variance accounted for by each cluster of predictors when it was included once the other one had already been introduced in the meta-regression model. The increase in $R^{2}$ when the parental involvement cluster was included in the model was $10.2 \%$, and statistically significant $(p<.001)$. Adding the cluster of treatment techniques provided an increase in $R^{2}$ of $12.2 \%$, which was also statistically significant $(p<.001)$.

\section{Meta-analysis in the Follow-Up}

Thirty of the 54 CBT groups analyzed reported data in the follow-up, but anyone study reported data for the control groups. In order to examine if the benefits of the therapy maintained over time, the standardized mean difference was computed between the pretest and the longest follow-up reported in the study. With regard to the distribution of the effect sizes, the results showed a greater improvement than in the posttest in the majority of the outcome measures. For global obsessive-compulsive measures, the mean effect was of very large magnitude and statistically significant $\left(d_{+}=2.189 ; 95 \%\right.$ C.I.: $\left.1.808,2.570 ; k=30\right)$. Results of a large magnitude were also found for anxiety measures $\left(d_{+}=0.938\right.$; $95 \%$ C.I.: $\left.0.597,1.278 ; k=13\right)$, depression $\left(d_{+}=0.662 ; 95 \%\right.$ C.I.: $\left.0.461,0.862 ; k=11\right)$, functional impairment $\left(d_{+}=1.153\right.$; 95\% C.I.: $\left.0.764,1.541 ; k=9\right)$, and other measures $\left(d_{+}=1.845\right.$; $95 \%$ C.I.: $1.209,2.481$; $k=12$ ). The only exception was family adaptation, whose mean effect was very low and non statistically significant $\left(d_{+}=0.150 ; 95 \%\right.$ C.I.: $\left.-0.396,0.696 ; k=5\right)$.

\section{Discussion}

The purpose of this research was to investigate the differential efficacy of psychological treatments for pediatric OCD. With this aim, a meta-analysis was conducted with a total of 62 groups reported in 46 studies. Fifty-four groups tested the efficacy of CBT and seven were control groups. The effect size index was the standardized mean of the pretest-posttest (follow-up) change scores. The problems with the internal validity of the $d$ index obtained from onegroup designs, led us to propose an adjusted mean effect, $d_{\mathrm{adj}}$, computing the difference between the mean $d$ indices of the treatment, $d_{\mathrm{T}}$, and the control, $d_{\mathrm{C}}$, groups $\left(d_{\mathrm{adj}}=d_{\mathrm{T}}-d_{\mathrm{C}}\right)$. The adjusted index allowed us to control the testing effects and, as a consequence, it offered a more appropriate estimate of the true treatment effect. With regard to obsessive-compulsive symptoms, the adjusted mean effect was $d_{\text {adj }}=1.628$, very similar to that obtained by Abramowitz et al. (2005) if we calculate the difference between the treatment and the control mean $d$ s reported by them: $d_{\mathrm{adj}}=d_{\mathrm{T}}-d_{\mathrm{C}}=$ $1.98-0.48=1.50$. A similar estimate was obtained by Watson and Rees (2008) with the five CBT-control comparisons included in their meta-analysis: $d_{\mathrm{adj}}=1.45$. The effect estimates for CBT obtained by O'Kearney (2007) and Freeman et al. (2007) were slightly lower than ours. O'Kearney (2007) reported a mean effect $d_{\mathrm{adj}}=1$, and Freeman et al. (2007) obtained an unadjusted mean effect $d=1.55$. Freeman et al. (2007) did not offer a mean $d$ for the control groups, but if we take the mean $d$ obtained with our control groups (or those from Abramowitz et al., 2005), then their adjusted estimation is similar to that offered by O'Kearney (2007): $d_{\mathrm{adj}}=d_{\mathrm{T}}-d_{\mathrm{C}}=1.55-0.48=1.07$. An analysis of publication bias enabled us to discard this as a threat to the validity of our results.

A result not found in previous meta-analyses on pediatric OCD was the larger effect size obtained with clinician assessments in comparison with those from self-reports. Another result not addressed previously concerns the effect estimates of the treatments on other related outcome measures. Our results showed statistically significant differences between the mean effects of CBT and control groups for anxiety and depression measures, with low-to-medium adjusted mean effect sizes $\left(d_{\mathrm{adj}}=0.470\right.$ and 0.319 , respectively). The lower effect of CBT on general anxiety and depression symptoms in comparison with that of obsessive-compulsive ones can be due to the fact that the treatments did not directly target these symptoms. Concerning family adaptation, the adjusted mean effect was of a medium magnitude $\left(d_{\text {adj }}=0.469\right)$, but not statistically significant. A statistically significant adjusted mean effect and of a large magnitude was obtained for other outcome measures $\left(d_{\mathrm{adj}}=1.383\right)$. Regarding functional impairment, the studies did not report data from control groups; so, it was not possible to obtain an adjusted effect size of the benefits achieved by CBT on these measures. Therefore, although the standardized pretest-posttest change scores index exhibited statistically significant improvements for the treatment groups in functional impairment, these results do not enable us to offer an accurate estimate of the benefits of CBT on these symptoms. The follow-up data showed large, statistically significant mean effects for obsessivecompulsive, anxiety, depression, functional impairment, 
and other measures. However, the absence of data from control groups did not allow us to obtain adjusted effect sizes. Therefore, follow-up results must be interpreted with caution.

The large heterogeneity exhibited by the effect sizes for obsessive-compulsive outcomes led us to examine the influence of the study characteristics. With regard to treatment characteristics, parental involvement in the therapy and the inclusion of relapse prevention techniques seem to be the most relevant components to improve the benefits of CBT in reducing obsessivecompulsive symptoms. These characteristics were included in the two treatment protocols that reached the largest effect sizes, the one applied by Barrett et al. (2004), with $d=3.188$, and the intensive CBT applied by Lewin et al. (2005), with $d=3.198$. Following the same line, our predictive model showed statistically significant increases in the variance accounted for when both the cluster of parental involvement $(10.2 \%)$ and the cluster of treatment techniques $(12.2 \%)$ were added to the model. Although previous research has found ERP as the main component of CBT to benefit patients with pediatric OCD, the results of our multiple metaregression did not find a statistically significant result for ERP, being relapse prevention the only treatment component than exhibited a positive, statistically significant result. One reason for not finding a statistical association between ERP and effect size is that the majority of the CBT groups (47 out of the 54 CBT groups) included ERP as a treatment component, making it difficult to achieve statistical significance. Another tentative explanation of this counterintuitive result is that the studies that reported using relapse prevention were also the better-conducted ones, hence explaining the significant finding in the meta-regression.

Previous meta-analyses on the efficacy of CBT for pediatric OCD did not present data about the differential efficacy due to treatment techniques. Only Freeman et al. (2007) found greater effect sizes for family-based CBT $(d=1.88)$ and individual CBT $(d=1.77)$ in comparison with group CBT $(d=0.76)$. The mean effects obtained by Freeman et al. (2007) were based on the standardized pretest-posttest difference for the CBT groups. Our results with the same effect size index were clearly larger than those obtained by Freeman et al. (2007): $d=2.035$ for family-based CBT, $d=2.017$ for individual CBT, and $d=1.781$ for group CBT (see Table 3). If we adjust our mean effect for these three CBT categories by subtracting the mean effect for the control groups $(d=0.232)$, we can obtain a more realistic benefit of CBT for family-based $\left(d_{\mathrm{adj}}=1.803\right)$, individual $\left(d_{\mathrm{adj}}=1.785\right)$, and group CBT $\left(d_{\mathrm{adj}}=1.549\right)$.

The training level of the therapists showed a negative, marginally statistically significant relationship with the effect sizes $(p=.065)$, with $11.8 \%$ of variance accounted for. This was an unexpected result, as previous research has found a null relationship between therapist's experience and treatment efficacy. Thus, van Oppen et al. (2010) found that clinically inexperienced master's students with no post-graduate training can be as capable as experienced behavior therapists in treating OCD patients, as long as therapists adhere to a manualized treatment and adequate training and supervision is provided. In addition, Webb, DeRubeis, and Barber (2010) conducted a meta-analysis about the relationship between therapist competence and outcome treatment and they found a practically null correlation between them $(r=.07)$. A tentative explanation for the negative relationship found in our meta-analysis between therapist's training and effect size might be that young clinicians often work harder than senior clinicians and pay more attention to details. Another explanation is the existence of a correlation between the training level of therapists and the treatment techniques applied in the studies, but this possible relationship was not explored due to the large number of techniques included in the studies. And another explanation of this unexpected result is the ambiguity in the studies to describe the therapist's experience.

With regards to the participants' characteristics, it was not possible to analyze some of these (e.g., family history of the disorder and type of obsessions/compulsions) due to the lack of information on these characteristics reported in the studies. None of the variables analyzed in our meta-analysis about the characteristics of the participants reached a statistical relationship with the effect sizes (age, gender, OCD history, previous treatments, comorbidity). These results must be interpreted cautiously, due to the low sensitivity of meta-analytic techniques in examining the influence of these characteristics. Previous meta-analyses did not explore the moderating effect of participant variables.

In our meta-analysis the effect size was not affected by methodological variables such as attrition of treatment groups in the posttest or the methodological quality of the studies. On the contrary, O'Kearney (2007) found that the studies with low risk of bias (according to methodological quality) tended to obtain lower effect sizes than the studies with high risk. In this respect, differences in how the study quality was assessed may explain the discrepant results between the meta-analyses.

One of the clearest implications for clinical practice is the convenience of using CBT for treating children and adolescents with OCD, since the improvements are very notable in reducing obsessive-compulsive symptoms and, in a lesser extent, anxiety, depression, family adaptation, functional impairment, and other symptoms. 
Concerning the treatment techniques, our findings suggest that the most promising treatments are those based on multicomponent programs comprising ERP, cognitive strategies, and relapse prevention. With the use of ERP children are exposed to feared objects, preventing them from performing avoiding responses (compulsions). Through this method, consecution of negative reinforcement is avoided, and the anxiety levels are reduced through the habituation process. Cognitive training intends to change beliefs and cognitive bias that maintain the obsessive-compulsive disorder, such as exaggerated sense of responsibility (Salkovskis et al., 2000), thought-action fusion (Rachman, 1993) or externalizing OCD (March \& Mulle, 1998). The latter refers to the ability of children to think about the disorder as an enemy separated from themselves. In relapse prevention sessions the therapist provides the child and family with coping techniques for future problems. In this sense, the factor that plays the most important role in the treatment is parental involvement. Parents can actively participate, on the one hand, in the assessment and reporting of more objective data and information and, on the other hand, in the implementation of the treatment, reducing accommodation to symptoms, applying exposure at home, and modifying beliefs and attitudes toward OCD (AACAP Committee on Quality Issues, 2012; Barrett et al., 2008). Currently, there are several standardized protocols that present the mentioned characteristics. Three of them present the highest effect sizes in our meta-analysis: Lewin et al.'s (2005) intensive CBT, Barrett's (2004) FOCUS protocol, and Lebowitz et al.'s (2013) intervention. In spite of the empirical support for these protocols, their application in clinical practice is not very common, with only one third of clinicians applying them routinely (AACAP Committee on Quality Issues, 2012). Our findings strongly recommend the routine application of these protocols by professionals.

Finally, the assessment of OCD requires an exhaustive collection of information by the therapist. Therefore, the use of validated measures and systematic observation constitute key elements for achieving this goal. At present, the most representative instrument for the assessment of pediatric OCD is the CY-BOCS.

Despite the great advances achieved in this field, there are still few experimental studies with control groups. The absence of control groups in the studies force meta-analysts to use an effect size index with low internal validity, conditioning the scope of the results of the primary studies and of the meta-analyses. In this sense, including two (or more) group designs with random allocation of the participants to the groups, as well as psychological placebo control conditions in the primary studies will allow the estimation of the nonspecific effects of the interventions for pediatric OCD. In addition, follow-up measurements should be carried out in the control groups in order to obtain a valid estimate of the long-term effects of the treatments.

Our recommendation on which treatment components are the most relevant to reduce obsessivecompulsive symptoms in pediatric OCD must be taken very cautiously, as meta-analysis is not an experimental research, but an observational one. The results of our multiple meta-regression model to examine the relative contributions of different treatment components are not based on an experimental design that dismantles CBT components. Multiple regression models applied in the context of a meta-analysis allow us to find a subset of study characteristics that can be statistically associated to the effect sizes taking into account the multicollinearity among them. However, regression models in meta-analysis cannot be employed to establish cause-effect relationships, but only statistical associations between the predictors and the effect sizes (López-López, Marín-Martínez, Sánchez-Meca, Van den Noortgate, \& Viechtbauer, 2014; Raudenbush, 2009). Following the same line, the results obtained in our multiple meta-regression model are only tentative, requiring caution throughout their interpretation, and should be used to guide future research on this topic. Thus, future experimental research should assess the differential effectiveness of the protocols and treatment techniques with the goal of improving the cost-effectiveness trade-off. This goal can be addressed by dismantling the treatments or by conducting face-to-face studies (e.g., ERP alone vs. ERP + cognitive training). In this sense, it would have been interesting to analyze differences depending on the kind of cognitive techniques used in the studies, but the scarce information reported by the majority of the empirical studies did not allow us to do so. Furthermore, family-based treatments must be studied in greater depth, as they seem to be very promising. In addition, the differential efficacy of the standardized protocols such as FOCUS, POTS, or Lewin et al.'s intensive CBT, should be examined by designing controlled studies that directly compare their efficacy. On the other hand, as Barrett et al. (2008) suggested, treatments must present enough flexibility to address the differing needs of individual families coming for treatment. It is also necessary to conduct studies analyzing differential efficacy according to variables indicated by some studies such as anxiety of parents, age or gender of participants (Böguels \& Phares, 2008; Creswell \& Cartwright-Hatton, 2007; McLeod et al., 2007). It is also relevant to develop strategies for treating non-responders, taking into account such factors as comorbidity or family functioning (Krebs \& Heyman, 2010). 
Finally, the information provided by primary studies should be more exhaustive and should report variables such as comorbidity, family history of the disorder, or type of obsessions/compulsions, among others. Moreover, the studies did not report all of the information needed to code all moderator variables included in our meta-analysis. A more comprehensive reporting of the relevant variables in the primary studies would not only facilitate the conducting of meta-analyses, but also the replication of empirical studies. Missing information about moderator variables in the studies limits the scope and generalizability of our metaanalytic findings. Although the results of our moderator analyses must be interpreted cautiously, they can help to guide the design and reporting of future research on this topic.

\section{References}

Abramowitz J. S., Whiteside S. P., \& Deacon B. J. (2005).

The effectiveness of treatment for pediatric obsessivecompulsive disorder: A meta-analysis. Behavior Therapy, 36, 55-63. http://dx.doi.org/10.1016/S0005-7894 (05)80054-1

American Academy of Child and Adolescent Committee on Quality Issues (2012). Practice parameter for the assessment and treatment of children and adolescents with obsessive-compulsive disorder. Journal of the American Academy of Child and Adolescent Psychiatry, 51, 98-113.

American Psychiatric Association. (2013). Diagnostic and statistical manual of mental disorders (DSM- $V$-TR). Washington, DC: American Psychiatric Association.

Barrett P. M., Farrell L., Pina A. A., Peris T. S., \& Piacentini J. (2008). Evidence-based psychosocial treatments for child and adolescent obsessive-compulsive disorder. Journal of Clinical Child and Adolescent Psychology, 37, 131-155. http:/ /dx.doi.org/10.1080/15374410701817956

Barrett P. M., Healy-Farrell L., \& March J. S. (2004). Cognitive-behavioral family treatment of childhood obsessive compulsive disorder: A controlled trial. Journal of the American Academy of Child and Adolescent Psychiatry, 43, 46-62. http:/ / dx.doi.org/10.1097/00004583200401000-00014

Becker B. J. (2005). Failsafe $\mathrm{N}$ or file-drawer number. In H. R. Rothstein, A. J. Sutton, \& M. Borenstein (Eds.), Publication bias in meta-analysis: Prevention, assessment and adjustments (pp. 111-125). Chichester, UK: Wiley.

Benazon N. R., Moore G. J., \& Rosenberg D. R. (2003). Neurochemical analyses in pediatric obsessive-compulsive disorder in patients treated with cognitive-behavioral therapy. Journal of American Academy of Child and Adolescent Psychiatry, 42, 1279-1285. http://dx.doi.org/10.1097/01. chi.0000087562.01900.de

Berg C. J., Rapoport J. L., \& Flament M. (1986). The Leyton Obsessional Inventory - Child Version. Journal of the American Academy of Child and Adolescent Psychiatry, 25, 84-91. http:/ /dx.doi.org/10.1016/S0002-7138(09)60602-6

Björgvinsson T., Wetterneck C. T., Powell D. M., Chasson G. S, Webb S. A, Hart, ... Stanley M. A. (2008).
Treatment outcome for adolescent obsessive-compulsive disorder in a specialized hospital setting. Journal of Psychiatric Practice, 14, 137-145. http:/ /dx.doi.org/ 10.1097/01.pra.0000320112.36648.3e

Bögels S., \& Phares V. (2008). Fathers' role in the etiology, prevention and treatment of child anxiety: A review and new model. Clinical Psychology Review, 28, 539-558. http:/ / dx.doi.org/10.1016/j.cpr.2007.07.011

Bolton D., Collins S., \& Steinberg D. (1983). The treatment of obsessive-compulsive disorder in adolescence: A report of 15 cases. British Journal of Psychiatry, 142, 456-464. http:/ /dx.doi.org/10.1192/bjp.142.5.456

Bolton D., \& Perrin S. (2008). Evaluation of exposure with response-prevention for obsessive compulsive disorder in childhood and adolescence. Journal of Behavior Therapy and Experimental Psychiatry, 39, 11-22. http:/ /dx.doi.org/ 10.1016/j.jbtep.2006.11.002

Bolton D., Williams T., Perrin S., Atkinson L., Gallop C., Waite P., \& Salkowskis P. (2011). Randomized controlled trial of full and brief cognitive-behavior therapy and wait-list for pediatric obsessive-compulsive disorder. Journal of Child Psychology and Psychiatry, 52, 1269-1278. http:/ /dx.doi.org/10.1111/j.1469-7610.2011.02419.x

Borenstein M. J., Hedges L. V., Higgins J., \& Rothstein H. (2009). Introduction to meta-analysis. Chichester, UK: Wiley.

Chambless D. L., Baker M. J., Baucom D. H., Beutler L. E., \& Calhoun K. S. (1998). Update on empirically validated therapies, II. The Clinical Psychologist, 51, 3-16.

Chambless D. L., \& Hollon S. D. (1998). Defining empirically supported therapies. Journal of Consulting and Clinical Psychology, 66, 7-18. http:/ /dx.doi.org/ 10.1037/0022-006X.66.1.7

Cohen J. (1988). Statistical power analysis for the behavioral sciences ( $2^{\text {nd }}$ Ed.). Hillsdale, NJ: Erlbaum.

Comer J., Furr J., Cooper-Vince C., Kerns C., Chan P., Edson A., \& ... Freeman J. (2014). Internet-delivered, family-based treatment for early-onset OCD: A preliminary case series. Journal of Clinical Child and Adolescent Psychology, 43, 74-87. http://dx.doi.org/10.1080/ 15374416.2013.855127

Creswell C., \& Cartwright-Hatton S. (2007). Family treatment of child anxiety: Outcomes, limitations and future directions. Clinical Child and Family Psychology, 10, 232-252. http:/ / dx.doi.org/10.1007/s10567-007-0019-3

De Haan E., Hoogduin K. A. L., Buitelaar J. K., \& Keijsers G. P. J. (1998). Behavior therapy versus clomipramine for treatment of obsessive-compulsive disorder in children and adolescents. Journal of the American Academy of Child and Adolescent Psychiatry, 37, 1022-1029. http:/ /dx.doi.org/10.1097/00004583-199810000-00011

Epstein N. B., Baldwin L. M., \& Bishop D. S. (1983). McMaster Family Assessment Device. Journal of Marital Family Therapy, 9, 171-180. http://dx.doi.org/10.1111/ j.1752-0606.1983.tb01497.x

Farrell L. J., Schlup B., \& Boschen M. J. (2010). Cognitivebehavioral treatment of childhood obsessive-compulsive disorder in community-based clinical practice: Clinical significance and benchmarking against efficacy. Behavior Research and Therapy, 48, 409-417. http:/ /dx.doi.org/ 10.1016/j.brat.2010.01.004 
Farrell L. J., Waters A. M., Boschen M. J., Hattingh L., McConnell H., Milliner E. L., ... Storch E. A. (2013). Dificult-to-treat pediatric obsessive-compulsive disorder: Feasibility and preliminary results of a randomized pilot trial of d-cycloserine-augmented behavior therapy. Depression and Anxiety, 30, 723-731.

Farrell L., Waters A., Milliner E., \& Ollendick T. (2012). Comorbidity and treatment response in pediatric obsessive-compulsive disorder: A pilot study of group cognitive-behavioral treatment. Psychiatry Research, 199, 115-123. http:/ / dx.doi.org/10.1016/j.psychres.2012.04.035

Fischer D. J., Himle J. A., \& Hanna G. L. (1998). Group behavioral therapy for adolescents with obsessivecompulsive disorder: Preliminary outcomes. Research on Social Work Practice, 8, 629-636. http:/ /dx.doi.org/ $10.1177 / 104973159800800601$

Franklin M. E., Kozak M. J., Cashman L. A., Coles M. E., Rheingold A. A., \& Foa E. B. (1998). Cognitive-behavioral treatment of pediatric obsessive-compulsive disorder: An open clinical trial. Journal of the American Academy of Child and Adolescent Psychiatry, 37, 412-419. http://dx.doi. org/10.1097/00004583-199804000-00019

Freeman J. B., Choate-Summers M. L., Moore P. S., Garcia A. M., Sapyta J. J., Leonard H. L., \& Franklin M. E. (2007). Cognitive behavioral treatment for young children with obsessive-compulsive disorder. Biological Psychiatry, 61, 337-343. http://dx.doi.org/10.1016/j.biopsych.2006. 12.015

Freeman J. B., Garcia A. M., Coyne L., Ale C., Przeworski A., Himle M., ... Leonard H. L. (2008). Early childhood OCD: Preliminary findings from a family-based cognitivebehavioral approach. Journal of the American Academy of Child and Adolescent Psychiatry, 47, 593-602. http://dx.doi. org/10.1097/CHI.0b013e31816765f9

Guy W. (1976). Assessment manual for psychopharmacology, revised (DHEW Publication No. ABM 76-366). Washington, DC: US Government Printing Office.

Hamilton M. (1960). A rating scale for depression. Journal of Neurology, Neurosurgery and Psychiatry, 23, 56-61. http:/ / dx.doi.org/10.1136/jnnp.23.1.56

Hedges L. V., \& Olkin I. (1985). Statistical methods for meta-analysis. Orlando, FL: Academic Press.

Himle J. A., Fischer D. J., Van Etten M., Janeck A., \& Hanna G. L. (2003). Group behavioral therapy for adolescents with tic-related and non-tic related obsessivecompulsive disorder. Depression and Anxiety, 17, 73-77. http:/ /dx.doi.org/10.1002/da.10088

Himle J. A. (2003). Group cognitive behavioral therapy for obsessive compulsive disorder: A review. Brief Treatment and Crisis Intervention, 3, 217-229. http:/ / dx.doi.org/ 10.1093/brief-treatment/mhg016

Keeley M. L., Geffken G. R., Ricketts E., McNamara J. H., \& Storch E. A. (2011). The therapeutic alliance in the cognitive behavioral treatment of pediatric obsessive-compulsive disorder. Journal of Anxiety Disorders, 25, 855-863.

Kovacs M. K. (1992). Child Depression Inventory. New York, NY: Multi-Health Systems.

Krebs G., \& Heyman I. (2010). Treatment-resistant obsessive-compulsive disorder in young people: Assessment and treatment strategies. Child and Adolescent
Mental Health, 15, 2-11. http://dx.doi.org/10.1111/j.14753588.2009.00548.x

Lewin A. B., Storch E. A., Adkins J., Murphy T. K., \& Geffken G. R. (2005). Current directions in pediatric obsessive-compulsive disorder. Pediatric Annual, 34, 128-134. http:/ / dx.doi.org/10.3928/0090-448120050201-11

Lebowitz E. R. (2013). Parent-based treatment for childhood and adolescent OCD. Journal of Obsessive-Compulsive and Related Disorders, 2, 425-431. http:/ /dx.doi.org/10.1016/ j.jocrd.2013.08.004

López-López J. A., Marín-Martínez F., Sánchez-Meca J., Van den Noortgate W., \& Viechtbauer W. (2014). Estimation of the predictive power of the model in mixed-effects meta-regression: A simulation study. British Journal of Mathematical and Statistical Psychology, 67, 30-48. http:/ /dx.doi.org/10.1111/bmsp.12002

March J. S. (1995). Cognitive-behavioral psychotherapy for children and adolescents with obsessive-compulsive disorder: A review and recommendations for treatment. Journal of the American Academy of Child and Adolescent Psychiatry, 34, 7-18. http:/ /dx.doi.org/10.1097/00004583199501000-00008

March J. S., Franklin M., Nelson A., \& Foa E. (2001). Cognitive-behavioral psychotherapy for pediatric obsessive compulsive disorder. Journal of Clinical Child Psychology, 30, 8-18. http:/ /dx.doi.org/10.1207/ S15374424JCCP3001_3

March J. S., \& Mulle K. (1998). OCD in children and adolescents: A cognitive-behavioral treatment manual. New York, NY: Guilford.

March J. S., Mulle K., \& Herbel B. (1994). Behavioral psychotherapy for children and adolescents with obsessive-compulsive disorder: An open trial of a new protocol driven treatment package. Journal of the American Academy of Child and Adolescent Psychiatry, 33, 333-341. http:/ /dx.doi.org/10.1097/00004583-199403000-00006

March J. S., Parker J. D. A., Sullivan K., Stallings P., \& Conners C. K. (1997). The Multidimensional Anxiety Scale for Children: Factor structure, reliability, and validity. Journal of the American Academy of Child and Adolescent Psychiatry, 36, 554-565. http:/ /dx.doi.org/10.1097/ 00004583-199704000-00019

Martin J., \& Thienemann M. (2005). Group cognitivebehavior therapy with family involvement for middleschool-age children with obsessive-compulsive disorder: A pilot study. Child Psychiatry and Human Development, 36, 113-127.

National Institute of Mental Health. (1985). Rating scales and assessment instruments for use in pediatric psychopharmacology research. Psychopharmacological Bulletin, 21, 839-843.

McLeod B. D., Wood J. J., \& Weisz J. R. (2007). Examining the association between parenting and childhood anxiety: A meta-analysis. Clinical Psychology Review, 27, 155-172. http:/ /dx.doi.org/10.1016/j.cpr.2006.09.002

Merlo L. J., Lehmkuhl H. D., Geffken G. R., \& Storch E. A. (2009). Decreased family accommodation associated with improved therapy outcome in pediatric obsessivecompulsive disorder. Journal of Consulting and Clinical 
Psychology, 77, 355-360. http:/ /dx.doi.org/10.1037/ a0012652

O'Kearney R. (2007). Benefits of cognitive-behavioral therapy for children and youth with obsessive-compulsive disorder: Re-examination of the evidence. Australian and New Zealand Journal of Psychiatry, 41, 199-212. http:/ /dx. doi.org/10.1080/00048670601172707

Olino T. M., Gillo S. M. A., Rowe D., Palermo S., Nuhfer E. C., Birmaher B., \& Gilbert A. R. (2011). Evidence for successful implementation of exposure and response prevention in a naturalistic group format for pediatric OCD. Depression and Anxiety, 28, 342-348. http:/ / dx.doi.org/10.1002/da.20789

Pediatric OCD Treatment Study (POTS) Team (2004). Cognitive-behavior therapy, sertraline, and their combination for children and adolescents with obsessivecompulsive disorder: The pediatric OCD treatment study (POTS) randomized controlled trial. Journal of the American Medical Association, 292, 1969-1976. http:/ /dx.doi. org/10.1001/jama.292.16.1969

Peris T., \& Piacentini J. (2013). Optimizing treatment for complex cases of childhood obsessive compulsive disorder: A preliminary trial. Journal of Clinical Child and Adolescent Psychology, 42, 1-8. http:/ /dx.doi.org/10.1080/ 15374416.2012.673162

Piacentini J., Bergman R. L., Jacobs C., McCracken J. T., \& Kretchman J. (2002). Open trial of cognitive behavior therapy for childhood obsessive-compulsive disorder. Journal of Anxiety Disorders, 16, 207-219. http:/ / dx.doi. org/10.1016/S0887-6185\%2802\%2900096-8

Piacentini J., \& Jaffer M. (1999). Measuring functional impairment in youngsters with OCD: Manual for the child OCD impact scale (COIS). Los Angeles, CA: UCLA Department of Psychiatry.

Piacentini J., \& Langley A. K. (2004). Cognitive-behavioral therapy for children who have obsessive-compulsive disorder. Journal of Clinical Psychology, 60, 1181-1194. http:/ / dx.doi.org/10.1002/jclp.20082

Piacentini J., Bergman R. L., Chang S., Langley A., Peris T., Wood J. J., \& McCracken J. (2011). Controlled comparison of family cognitive behavioral therapy and psychoeducation/ relaxation training for child obsessive-compulsive disorder. Journal of the American Academy of Child and Adolescent Psychiatry, 50, 1149-1161. http://dx.doi.org/10.1016/ j.jaac.2011.08.003

Poznanski E. O., Freeman L. N., \& Mokros H. B. (1985). Children's Depression Rating Scale-Revised. Psychopharmacology Bulletin, 21, 979-989.

Rachman S. (1993). Obsessions, responsibility, and guilt. Behaviour Research and Therapy, 31, 149-154. http:/ /dx.doi. org/10.1016/0005-7967(93)90066-4

Ramos-Asbahr F., Castillo A. R., Ito L. M., Latorre M. R., Moreira M. N., \& Lotufo-Neto F. (2005). Group cognitivebehavioral therapy versus sertraline for the treatment of children and adolescents with obsessive-compulsive disorder. Journal of the American Academy of Child and Adolescent Psychiatry, 44, 1128-1136. http:/ /dx.doi. org/10.1097/01.chi.0000177324.40005.6f

Rapoport J. L., Inoff-Germain G., Weissman M. M., Greenwald S., Narrow W. E., Jensen P. S., ... Canino G.
(2000). Childhood obsessive-compulsive disorder in the NIMH MECA study: Parent versus child identification of cases Methods for the epidemiology of child and adolescent mental disorders. Journal of Anxiety Disorders, 14, 535-548. http:/ /dx.doi.org/10.1016/S08876185(00)00048-7

Raudenbush S. W. (2009). Analyzing effect sizes: Randomeffects models. In H. Cooper, L. V. Hedges, \& J. C. Valentine (Eds.), The handbook of research synthesis and meta-analysis (2nd Ed., pp. 295-315). New York, NY: Russell Sage Foundation.

Reynolds S. A., Clark S., Smith H., Langdon P. E., Payne R., Bowers G., ... McIlwham H. (2013). Randomized controlled trial of parent-enhanced CBT compared with individual CBT for obsessive-compulsive disorder in young people. Journal of Consulting and Clinical Psychology, 81, 1021-1026. http:/ /dx.doi.org/10.1037/a0034429

Reynolds C. R., \& Richmond B. O. (1978). What I think I feel: A revised measure of children's manifest anxiety. Journal of Abnormal Child Psychiatry, 6, 271-280. http:/ / dx.doi.org/10.1007/BF00919131

Rezvan S., Bahrami F., Abedi M., Macleod C., Doost H., \& Ghasemi V. (2013). A preliminary study on the effects of attachment-based intervention on pediatric obsessivecompulsive disorder. International Journal of Preventive Medicine, 4, 78-87.

Robinson S., Turner C., Heyman I., \& Farquharson L. (2013). The feasibility and acceptability of a cognitivebehavioral self-help intervention for adolescents with obsessive-compulsive disorder. Behavioural and Cognitive Psychotherapy, 41, 117-122. http://dx.doi.org/10.1017/ S1352465812000562

Rosa-Alcázar A., Sánchez-Meca J., Gómez-Conesa A., \& Marín-Martínez F. (2008). Psychological treatment of obsessive-compulsive disorder: A meta-analysis. Clinical Psychology Review, 28, 1310-1325.

Salkovskis P., Wroe A., Gledhill A., Morrison N., Forrester E., Richards C., ... Thorpe S. (2000). Responsibility attitudes and interpretations are characteristic of obsessive compulsive disorder. Behaviour Research and Therapy, 38, 347-372. http:/ /dx. doi.org/10.1016/S0005-7967(99)00071-6

Sánchez-Meca J., \& Marín-Martínez F. (2008). Confidence intervals for the overall effect size in random-effects meta-analysis. Psychological Methods. 13, 31-48. http:/ /dx. doi.org/10.1037/1082-989X.13.1.31

Scahill L., Riddle M. A., McSwiggin-Hardin M., Ort S. I., King R. A., Goodman W. K., ..., Leckman J. F. (1997). Children's Yale-Brown Obsessive-Compulsive Scale: Reliability and validity. Journal of the American Academy of Child and Adolescent Psychiatry, 36, 844-852. http:/ /dx.doi. org/10.1097/00004583-199706000-00023

Scahill L., Vitulano L. A., Brenner E. M., Lynch K. A., \& King R. A. (1996). Behavioral therapy in children and adolescents with obsessive-compulsive disorder: A pilot study. Journal of Child and Adolescent Psychopharmacology, 6, 191-202. http:/ / dx.doi.org/10.1089/cap.1996.6.191

Shafran R., Frampton I., Heyman I., Reynolds M., Teachman B., \& Rachman S. (2003). The preliminary development of a new self-report measure for OCD in 
young people. Journal of Adolescence, 26, 137-142. http:/ / dx.doi.org/10.1016/S0140-1971(02)00083-0

Shaffer D., Fisher P., Lucas C. P., Dulcan M. K., \& Schwab-Stone M. E. (2000). NIMH Diagnostic Interview Schedule for Children Version IV (NIMH DICS-IV): Description, differences from previous versions, and reliability of some common diagnoses. Journal of the American Academy of Child and Adolescent Psychiatry, 39, 28-38.

Shaffer D., Gould M. S., Brasic J., Ambrosini P., Fisher P., Bird H., \& Aluwahlia S. (1983). A Children's Global Assessment Scale (CGAS). Formely Archives of General Psychiatry, 40, 1228-1231. http:/ /dx.doi.org/10.1001/ archpsyc.1983.01790100074010

Simons M., Schneider S., \& Herpertz-Dahlmann B. (2006). Metacognitive therapy versus exposure and response prevention for pediatric obsessive-compulsive disorder. Psychotherapy and Psychosomatics, 75, 257-264. http:// dx.doi.org/10.1159/000092897

Söchting I., \& Third B. (2011). Behavioral group treatment for obsessive-compulsive disorder in adolescence: A pilot study. International Journal of Group Psychotherapy, 61, 84-97.

Startup M., Jackson M. C., \& Bendix S. (2002). The concurrent validity of the Global Assessment of Functioning (GAF). British Journal of Clinical Psychology, 41, 417-422. http:/ /dx.doi.org/10.1348/014466502760387533

Storch E. A., Bagner D. M., Geffken G. R., Adkins J. W., Murphy T. K., \& Goodman W. K. (2007). Sequential cognitive-behavioral therapy for children with obsessivecompulsive disorder with and inadequate medication response: A case series of five patients. Depression and Anxiety, 24, 375-381. http://dx.doi.org/10.1002/da.20260

Storch E., Bussing R., Small B. J., Geffken G. R., McNamara J. P., Rahman O., ... Murphy T. K. (2013). Randomized, placebo-controlled trial of cognitivebehavioral therapy alone or combined with sertraline in the treatment of pediatric obsessive-compulsive disorder. Behaviour Research and Therapy, 51, 823-829. http:/ /dx.doi. org/10.1016/j.brat.2013.09.007

Storch E. A., Caporino N. E., Morgan J. R., Lewin A. B., Rojas A., Brauer L., ... Murphy T. K. (2011). Preliminary investigation of web-camera delivered cognitivebehavioral therapy for youth with obsessive-compulsive disorder. Psychiatry Research, 189, 407-412. http:/ / dx.doi. org/10.1016/j.psychres.2011.05.047

Storch E. A., Geffken G. R., Merlo L. J., Mann G., Duke D., Munson M., ... Goodman W. K. (2007). Family-based cognitive-behavioral therapy for pediatric obsessivecompulsive disorder: Comparison of intensive and weekly approaches. Journal of the American Academy of Child and Adolescent Psychiatry, 46, 469-478.

Storch E. A., Larson M. J., Muroff J., Caporino N., Geller D., Reid J. M., ... Murphy T. K. (2010). Predictors of functional impairment in pediatric obsessivecompulsive disorder. Journal of Anxiety Disorders, 24, 275-283. http:/ / dx.doi.org/10.1016/j.janxdis.2009.12.004

Storch E. A., Lehmkuhl H. D., Ricketts E., Geffken G. R., Marien W., \& Murphy T. K. (2010). An open trial of intensive family based cognitive-behavioral therapy in youth with obsessive-compulsive disorder who are medication partial responders or nonresponders. Journal of Clinical Child and Adolescent Psychology, 39, 260-268. http:/ /dx.doi.org/10.1080/15374410903532676

Storch E. A., Merlo L. J., Larson M. J., Bloss C. S., Geffken G. R., Jacob M. L., ... Goodman W. K. (2008). Symptom dimensions and cognitive-behavioral therapy outcome for pediatric obsessive-compulsive disorder. Acta Psychiatrica Scandinavica, 117, 67-75. http:/ /dx.doi. org/10.1111/j.1600-0447.2007.01113.x

Storch E. A, Murphy T. K., Geffken G. R., Mann G., Adkins J., Merlo L. J., ... Goodman W. K. (2006). Cognitivebehavioral therapy for PANDAS-related obsessivecompulsive disorder: Findings from a preliminary waitlist controlled open trial. Journal of the American Academy of Child and Adolescent Psychiatry, 45, 1171-1178. http://dx.doi. org/10.1097/01.chi.0000231973.43966.a0

Taylor S. (2011). Early versus late onset obsessivecompulsive disorder: Evidence for distinct subtypes. Clinical Psychology Review, 31, 1083-1100. http:/ / dx.doi. org/10.1016/j.cpr.2011.06.007

Thienemann M., Martin J., Cregger B., Thompson H., \& Dyer-Friedman J. (2001). Manual-driven group cognitivebehavioral therapy for adolescents with obsessivecompulsive disorder: A pilot study. Journal of the American Academy of Child and Adolescent Psychiatry, 40, 1254-1260. http:/ / dx.doi.org/10.1097/00004583-200111000-00004

Turner C. M. (2006). Cognitive-behavioral theory and therapy for obsessive-compulsive disorder in children and adolescents: Current status and future directions. Clinical Psychology Review, 26, 912-938. http:/ /dx.doi. org/10.1016/j.cpr.2005.10.004

Turner C., Heyman I., Futh A., \& Lovell K. (2009). A pilot study of telephone cognitive-behavioral therapy for obsessive-compulsive disorder in young people. Behavioral and Cognitive Psychotherapy, 37, 469-474. http://dx.doi. org/10.1017/S1352465809990178

Valderhaug R., \& Ivarsson T. (2005). Functional impairment in clinical samples of Norwegian and Swedish children and adolescents with obsessive-compulsive disorder. European Child and Adolescent Psychiatry, 14, 164-173. http:/ /dx.doi.org/10.1007/s00787-005-0456-9

Valderhaug R., Larsson B., Götestam K. G., \& Piacentini J. (2007). An open clinical trial of cognitive-behavior therapy in children and adolescents with obsessive-compulsive disorder administered in regular outpatient clinics. Behavior Research and Therapy, 45, 577-589. http:/ /dx.doi. org/10.1016/j.brat.2006.04.011

van Oppen P., van Balkom A. J. L. M., Smit J. H., Schuurmans J., van Dyck R., \& Emmelkamp P. M. G. (2010). Does the therapy manual or the therapist matter most in treatment of obsessive-compulsive disorder? A randomized controlled trial of exposure with response or ritual prevention in 118 patients. Journal of Clinical Psychiatry, 71, 1158-1167. http:/ /dx.doi.org/10.4088/ JCP.08m04990blu

Wagner A. P. (2003). Cognitive-behavioral therapy for children and adolescents with obsessive compulsive disorder. Brief Treatment and Crisis Intervention, 3, 291-306. http:/ /dx.doi.org/10.1093/brief-treatment/mhg022 
Waters T. L., Barrett P., \& March J. S. (2001). Cognitivebehavioral family treatment of childhood obsessivecompulsive disorder: Preliminary findings. American Journal of Psychotherapy, 55, 372-387.

Watson H. J., \& Rees C. S. (2008). Meta-analysis of randomized, controlled treatment trials for pediatric obsessive-compulsive disorder. Journal of Child Psychology and Psychiatry and Allied Disciplines, 49, 489-498. http:/ / dx.doi.org/10.1111/j.1469-7610.2007.01875.x

Webb C. A., DeRubeis R. J., \& Barber J. P. (2010). Therapist adherence/competence and treatment outcome: A meta-analytic review. Journal of Consulting and Clinical Psychology, 78, 200-211. http://dx.doi.org/10.1037/ a0018912

Whiteside S. P., \& Jacobsen A. B. (2010). An uncontrolled examination of a 5-day intensive treatment for pediatric
OCD. Behavior Therapy, 41, 414-422. http:/ /dx.doi. org/10.1016/j.beth.2009.11.003

Williams T. I., Salkovskis P. M, Forrester L., Turner S., White H., \& Allsop M. A. (2010). A randomized controlled trial of cognitive behavioral treatment for obsessive compulsive disorder in children and adolescents. European Journal of Children and Adolescents Psychiatry, $19,449-456$.

Wolff R. P., \& Wolff L. S. (1991). Assessment and treatment of obsessive-compulsive disorder. Children Behavior Modification, 15, 372-393. http:/ /dx.doi. org $/ 10.1177 / 01454455910153006$

Zohar A. H. (1999). The epidemiology of obsessivecompulsive disorder in children and adolescents. Child and Adolescent Psychiatric Clinics of North America, 8 , 445-460. 
Appendix.

Some of the moderator variables of the studies included in the meta-analysis.

\begin{tabular}{|c|c|c|c|c|c|c|c|c|c|c|c|}
\hline Study & $N$ & $\begin{array}{l}\text { Mean } \\
\text { age }\end{array}$ & Gender & $\begin{array}{l}\text { OCD } \\
\text { history }\end{array}$ & $\begin{array}{l}\text { Treatment } \\
\text { techniques }\end{array}$ & $\begin{array}{l}\text { Treatment } \\
\text { duration }\end{array}$ & $\begin{array}{l}\text { treatment } \\
\text { intensity }\end{array}$ & $\begin{array}{l}\text { Parent } \\
\text { involvement }\end{array}$ & $\begin{array}{l}\text { Design } \\
\text { quality }\end{array}$ & Design & $d$ \\
\hline $\begin{array}{l}\text { Barrett et al. } \\
\text { (2004)a }\end{array}$ & 24 & 10.8 & 50.0 & - & $\mathrm{PE}+\mathrm{ERP}+\mathrm{CT}+\mathrm{RP}$ & 14 & 1.5 & High & 5.5 & RCT & 3.297 \\
\hline $\begin{array}{l}\text { Barrett et al. } \\
\qquad(2004) b\end{array}$ & 29 & 12.9 & 45.0 & - & $\mathrm{PE}+\mathrm{ERP}+\mathrm{CT}+\mathrm{RP}$ & 14 & 1.5 & High & 5.5 & $\mathrm{RCT}$ & 3.093 \\
\hline $\begin{array}{l}\text { Barrett et al. } \\
\qquad(2004) c\end{array}$ & 24 & 11.8 & 54.2 & - & $\begin{array}{l}\text { Inactive control } \\
\text { group }\end{array}$ & - & - & - & 5.5 & $\mathrm{RCT}$ & -0.184 \\
\hline $\begin{array}{l}\text { Benazon et al. } \\
\text { (2003) }\end{array}$ & 23 & 11.7 & 52.2 & 3.24 & $\mathrm{PE}+\mathrm{ERP}+\mathrm{CT}+\mathrm{RP}$ & 12 & 1 & Medium & 2.9 & One-group & 2.457 \\
\hline $\begin{array}{l}\text { Björgvinsson } \\
\text { et al. (2008) }\end{array}$ & 23 & 15.3 & 52.2 & - & $\mathrm{PE}+\mathrm{ERP}+\mathrm{CT}+\mathrm{RP}$ & 9.5 & - & Medium & 1.9 & One-group & 0.834 \\
\hline $\begin{array}{l}\text { Bolton et al. } \\
\text { (1983) }\end{array}$ & 15 & 14.1 & 53.3 & 2.2 & $\mathrm{PE}+\mathrm{ERP}+\mathrm{CT}+\mathrm{BE}$ & - & - & High & 3.0 & One-group & 2.468 \\
\hline $\begin{array}{l}\text { Bolton \& Perrin } \\
\quad(2008) \mathrm{a}\end{array}$ & 10 & 13.0 & 60.0 & 1.79 & $P E+E R P+R P$ & 5 & 2 & Low & 3.8 & $\mathrm{RCT}$ & 2.427 \\
\hline $\begin{array}{l}\text { Bolton \& Perrin } \\
\quad(2008) b\end{array}$ & 10 & 13.0 & 80.0 & 1.8 & $\begin{array}{l}\text { Inactive control } \\
\text { group }\end{array}$ & - & - & - & 4.0 & $\mathrm{RCT}$ & 0.101 \\
\hline $\begin{array}{l}\text { Bolton et al. } \\
\text { (2011)a }\end{array}$ & 36 & 15.0 & 42.0 & 3.8 & $\mathrm{PE}+\mathrm{CT}+\mathrm{RP}$ & 12 & 1.17 & Medium & 4.45 & $\mathrm{RCT}$ & 1.772 \\
\hline $\begin{array}{l}\text { Bolton et al. } \\
\text { (2011)b }\end{array}$ & 36 & 14.4 & 36.0 & 3.0 & $\mathrm{PE}+\mathrm{CT}+\mathrm{RP}$ & 5 & 1.54 & Medium & 4.45 & $\mathrm{RCT}$ & 1.069 \\
\hline $\begin{array}{l}\text { Bolton et al. } \\
\text { (2011)c }\end{array}$ & 24 & 14.0 & 46.0 & 2.5 & $\begin{array}{l}\text { Inactive control } \\
\text { group }\end{array}$ & - & - & - & 4.87 & $\mathrm{RCT}$ & 0.090 \\
\hline $\begin{array}{l}\text { Comer et al. } \\
\text { (2014) }\end{array}$ & 5 & 6.5 & 60.0 & - & $\mathrm{PE}+\mathrm{ERP}+\mathrm{CT}$ & 14 & - & High & 3.0 & One-group & 1.064 \\
\hline $\begin{array}{l}\text { Farrell et al. } \\
\qquad(2010)\end{array}$ & 35 & 12.3 & 54.3 & - & $\mathrm{PE}+\mathrm{ERP}+\mathrm{CT}+\mathrm{RP}$ & 11.5 & 1.0 & High & 3.0 & One-group & 2.063 \\
\hline $\begin{array}{l}\text { Farrell et al. } \\
\text { (2013) }\end{array}$ & 8 & 13.11 & 41.0 & - & $\mathrm{PE}+\mathrm{ERP}+\mathrm{CT}+\mathrm{RP}$ & 9.0 & 1.5 & High & 5.5 & $\mathrm{RCT}$ & 2.455 \\
\hline $\begin{array}{l}\text { Farrell et al. } \\
\qquad(2012)\end{array}$ & 43 & 11.10 & 70.0 & - & $\mathrm{PE}+\mathrm{ERP}+\mathrm{CT}+\mathrm{RP}$ & 13.0 & 1.5 & High & 3.0 & One-group & 1.722 \\
\hline $\begin{array}{l}\text { Fischer et al. } \\
\text { (1998) }\end{array}$ & 15 & 14.5 & 60.0 & - & $\mathrm{PE}+\mathrm{ERP}+\mathrm{CT}$ & 7 & 1.5 & Medium & 3.0 & One-group & 0.741 \\
\hline $\begin{array}{l}\text { Franklin et al. } \\
\text { (1998)a }\end{array}$ & 7 & 14.1 & 71.4 & 5.2 & $\mathrm{PE}+\mathrm{ERP}+\mathrm{CT}+\mathrm{RP}$ & 4 & 6.75 & Medium & 2 & Two-group & 2.113 \\
\hline $\begin{array}{l}\text { Franklin et al. } \\
\qquad(1998) b\end{array}$ & 7 & 14.1 & 71.4 & 5.2 & $\mathrm{PE}+\mathrm{ERP}+\mathrm{RP}$ & 16 & 1 & Medium & 2 & Two-group & 1.565 \\
\hline $\begin{array}{l}\text { Freeman et al. } \\
\qquad(2008) \mathrm{a}\end{array}$ & 22 & 7.1 & 43.0 & 2.12 & $\mathrm{PE}+\mathrm{ERP}+\mathrm{CT}+\mathrm{RP}$ & 14 & 0.93 & High & 5.7 & $\mathrm{RCT}$ & 2.134 \\
\hline $\begin{array}{l}\text { Freeman et al. } \\
\qquad(2008) \mathrm{b}\end{array}$ & 20 & 7.1 & 43.6 & 2.12 & $\mathrm{PE}+\mathrm{BF}$ & 14 & 0.93 & Medium & 5.8 & $\mathrm{RCT}$ & 0.977 \\
\hline $\begin{array}{l}\text { Ginsburn et al. } \\
\text { (2001) }\end{array}$ & 7 & 6 & 42.8 & - & $\mathrm{PE}+\mathrm{ERP}+\mathrm{CT}+\mathrm{PR}$ & 12 & 1.25 & High & 2 & One-group & 1.369 \\
\hline $\begin{array}{l}\text { Haan et al. } \\
\text { (1998) }\end{array}$ & 12 & 13.3 & 50.0 & 3.11 & $\mathrm{PE}+\mathrm{ERP}+\mathrm{CT}+\mathrm{PR}$ & 12 & - & Low & 2.4 & $\mathrm{RCT}$ & 1.239 \\
\hline $\begin{array}{l}\text { Himle et al. } \\
\text { (2003) }\end{array}$ & 19 & 14.6 & 57.9 & 4.08 & $\mathrm{PE}+\mathrm{ERP}+\mathrm{CT}$ & 7 & 1.5 & Medium & 3.0 & One-group & 0.782 \\
\hline $\begin{array}{l}\text { Keeley et al. } \\
\quad(2011)\end{array}$ & 25 & 13.2 & 56.0 & 2.72 & $\mathrm{PE}+\mathrm{ERP}+\mathrm{CT}+\mathrm{RP}$ & 12 & - & Medium & 1.9 & One-group & 3.667 \\
\hline $\begin{array}{l}\text { Lebowitz et al. } \\
\qquad(2013)\end{array}$ & 6 & 11.3 & 66.6 & - & $\mathrm{PE}+\mathrm{CT}+\mathrm{RP}$ & 12 & - & High & 2 & One-group & 3.747 \\
\hline
\end{tabular}


Appendix. (Continued)

\begin{tabular}{|c|c|c|c|c|c|c|c|c|c|c|c|}
\hline Study & $N$ & $\begin{array}{l}\text { Mean } \\
\text { age }\end{array}$ & Gender & $\begin{array}{l}\text { OCD } \\
\text { history }\end{array}$ & $\begin{array}{l}\text { Treatment } \\
\text { techniques }\end{array}$ & $\begin{array}{l}\text { Treatment } \\
\text { duration }\end{array}$ & $\begin{array}{l}\text { Treatment } \\
\text { intensity }\end{array}$ & $\begin{array}{l}\text { Parent } \\
\text { involvement }\end{array}$ & $\begin{array}{l}\text { Design } \\
\text { quality }\end{array}$ & Design & $d$ \\
\hline $\begin{array}{c}\text { March et al. } \\
\text { (1994) }\end{array}$ & 15 & 14.3 & 33.3 & - & $\begin{array}{c}\mathrm{PE}+\mathrm{BF}+\mathrm{ERP} \\
+\mathrm{CT}+\mathrm{PR}\end{array}$ & 16 & - & Medium & 3.0 & One-group & 1.493 \\
\hline $\begin{array}{l}\text { Martin \& } \\
\text { Thienemann } \\
\text { (2005) }\end{array}$ & 14 & 11.3 & 31.0 & 2.5 & $\mathrm{PE}+\mathrm{ERP}+\mathrm{CT}+\mathrm{PR}$ & 14 & 1.5 & High & 2.5 & One-group & 0.968 \\
\hline $\begin{array}{l}\text { Merlo et al. } \\
\text { (2009) }\end{array}$ & 49 & 12.8 & 55.0 & - & $\mathrm{PE}+\mathrm{ERP}+\mathrm{CT}+\mathrm{RP}$ & 14 & 1.5 & High & 2.9 & One-group & 3.132 \\
\hline $\begin{array}{l}\text { Olino et al. } \\
\text { (2011) }\end{array}$ & 41 & 12.4 & 47.0 & - & $P E+E R P+R P$ & 12.1 & 8.6 & High & 3.0 & One-group & 0.778 \\
\hline $\begin{array}{l}\text { Peris \& Piacentini } \\
\quad \text { (2013)a }\end{array}$ & 10 & 12.35 & 55.0 & - & $\mathrm{PE}+\mathrm{EPR}+\mathrm{CT}+\mathrm{RP}$ & 12 & 1.0 & High & 4.5 & RCT & 4.599 \\
\hline $\begin{array}{l}\text { Peris \& Piacentini } \\
\quad \text { (2013)b }\end{array}$ & 10 & 12.35 & 55.0 & - & $\mathrm{PE}+\mathrm{EPR}+\mathrm{CT}+\mathrm{RP}$ & 12 & 1.5 & Medium & 4.5 & RCT & 1.993 \\
\hline $\begin{array}{l}\text { Piacentini et al. } \\
\text { (2002) }\end{array}$ & 42 & 11.8 & 40.0 & 4.9 & $\mathrm{PE}+\mathrm{ERP}+\mathrm{CT}+\mathrm{RP}$ & 10 & 1 & Medium & 3.0 & One-group & 2.044 \\
\hline $\begin{array}{l}\text { Piacentini et al. } \\
\text { (2011)a }\end{array}$ & 49 & 12.20 & 37.0 & - & $\mathrm{PE}+\mathrm{ERP}+\mathrm{CT}+\mathrm{RP}$ & 14 & 1.3 & High & 4.84 & $\mathrm{RCT}$ & 2.376 \\
\hline $\begin{array}{l}\text { Piacentini et al. } \\
\text { (2011)b }\end{array}$ & 22 & 12.20 & 37.0 & - & $\begin{array}{l}\text { PE+Relaxation } \\
\text { training }\end{array}$ & 14 & 1.3 & Medium & 4.77 & $\mathrm{RCT}$ & 1.973 \\
\hline POTS (2004)a & 25 & 11.4 & 50.0 & - & $\mathrm{PE}+\mathrm{ERP}+\mathrm{CT}+\mathrm{RP}$ & 12 & 1 & Medium & 5.9 & $\mathrm{RCT}$ & 2.526 \\
\hline POTS (2004)b & 21 & 12.3 & 50.0 & - & Pill-placebo group & - & - & - & 5.9 & $\mathrm{RCT}$ & 1.078 \\
\hline $\begin{array}{l}\text { Ramos et al. } \\
\text { (2005) }\end{array}$ & 20 & 13.7 & 75.0 & 4.8 & $\mathrm{PE}+\mathrm{ERP}+\mathrm{CT}$ & 12 & 1.5 & Medium & 4.9 & $\mathrm{RCT}$ & 3.283 \\
\hline $\begin{array}{l}\text { Reynolds et al. } \\
\text { (2013)a }\end{array}$ & 25 & 14.4 & - & - & $\mathrm{PE}+\mathrm{ERP}+\mathrm{CT}+\mathrm{RP}$ & 14 & - & Low & 4.9 & $\mathrm{RCT}$ & 2.122 \\
\hline $\begin{array}{l}\text { Reynolds et al. } \\
\text { (2013)b }\end{array}$ & 25 & 14.6 & - & - & $\mathrm{PE}+\mathrm{ERP}+\mathrm{CT}+\mathrm{RP}$ & 14 & - & High & 4.8 & $\mathrm{RCT}$ & 1.525 \\
\hline $\begin{array}{l}\text { Rezvan et al. } \\
\text { (2013)a }\end{array}$ & 12 & 10.3 & 0.0 & - & $\begin{array}{l}\text { Attachment-based } \\
\text { treat. }\end{array}$ & 8 & 1 & High & 4.0 & RCT & 1.674 \\
\hline $\begin{array}{l}\text { Rezvan et al. } \\
\text { (2013) b }\end{array}$ & 12 & 10.3 & 0.0 & - & $\begin{array}{l}\text { Inactive control } \\
\text { group }\end{array}$ & - & - & - & 4.0 & $\mathrm{RCT}$ & 0.112 \\
\hline $\begin{array}{l}\text { Robinson et al. } \\
\text { (2013) }\end{array}$ & 8 & 13.5 & 38.0 & 3 & $\mathrm{PE}+\mathrm{ERP}+\mathrm{CT}+\mathrm{RP}$ & 8 & - & Low & 2.5 & One-group & 0.382 \\
\hline $\begin{array}{l}\text { Scahill et al. } \\
\text { (1996) }\end{array}$ & 7 & 13.0 & 71.4 & 3.7 & $\mathrm{PE}+\mathrm{ERP}+\mathrm{RP}$ & 12 & - & High & 2.0 & One-group & 1.626 \\
\hline $\begin{array}{l}\text { Simons et al. } \\
\text { (2006)a }\end{array}$ & 5 & 14.5 & 50.0 & 0.47 & $\mathrm{PE}+\mathrm{CT}+\mathrm{BE}+\mathrm{RP}$ & 9 & - & Medium & 2.8 & $\mathrm{RCT}$ & 2.728 \\
\hline $\begin{array}{l}\text { Simons et al. } \\
\text { (2006)b }\end{array}$ & 5 & 13.4 & 80.0 & 0.82 & $\begin{array}{c}\mathrm{PE}+\mathrm{ERP}+\mathrm{CT} \\
+\mathrm{BE}+\mathrm{RP}\end{array}$ & 13 & - & Medium & 4.0 & $\mathrm{RCT}$ & 1.984 \\
\hline $\begin{array}{l}\text { Söchting \& Third } \\
\text { (2011) }\end{array}$ & 7 & 15.5 & 57.0 & - & $\mathrm{PE}+\mathrm{ERP}+\mathrm{CT}+\mathrm{RP}$ & 10 & 2 & Low & 2.0 & One-group & 1.363 \\
\hline $\begin{array}{l}\text { Storch, Lehmkuhl } \\
\text { et al. (2010) }\end{array}$ & 130 & 13.4 & 50.0 & - & $\mathrm{PE}+\mathrm{ERP}+\mathrm{CT}+\mathrm{RP}$ & 3 & 7 & High & 2.97 & One-group & 1.481 \\
\hline $\begin{array}{l}\text { Storch, Bagner } \\
\text { et al. (2007) }\end{array}$ & 5 & 9.6 & 80.0 & - & $\mathrm{PE}+\mathrm{ERP}+\mathrm{CT}+\mathrm{RP}$ & 3 & 7.5 & Low & 3.0 & One-group & 4.894 \\
\hline $\begin{array}{c}\text { Storch et al. } \\
\text { (2013) }\end{array}$ & 16 & 12.6 & 68.8 & - & $\mathrm{PE}+\mathrm{ERP}+\mathrm{CT}+\mathrm{RP}$ & 14 & 1 & Medium & 4.3 & $\mathrm{RCT}$ & 0.996 \\
\hline $\begin{array}{c}\text { Storch et al. } \\
\text { (2011)b }\end{array}$ & 15 & 11.1 & 61.0 & - & $\begin{array}{l}\text { Inactive control } \\
\text { group }\end{array}$ & - & - & - & 4.5 & $\mathrm{RCT}$ & 0.130 \\
\hline $\begin{array}{c}\text { Storch et al. } \\
\text { (2011)a }\end{array}$ & 16 & 11.1 & 61.0 & - & $\mathrm{PE}+\mathrm{ERP}+\mathrm{CT}+\mathrm{RP}$ & 12 & 1 & High & 4.5 & $\mathrm{RCT}$ & 1.973 \\
\hline
\end{tabular}


Appendix. (Continued)

\begin{tabular}{|c|c|c|c|c|c|c|c|c|c|c|c|}
\hline Study & $N$ & $\begin{array}{l}\text { Mean } \\
\text { age }\end{array}$ & Gender & $\begin{array}{l}\text { OCD } \\
\text { history }\end{array}$ & $\begin{array}{l}\text { Treatment } \\
\text { techniques }\end{array}$ & $\begin{array}{l}\text { Treatment } \\
\text { duration }\end{array}$ & $\begin{array}{l}\text { Treatment } \\
\text { intensity }\end{array}$ & $\begin{array}{l}\text { Parent } \\
\text { involvement }\end{array}$ & $\begin{array}{l}\text { Design } \\
\text { quality }\end{array}$ & Design & $d$ \\
\hline $\begin{array}{l}\text { Storch, Geffken } \\
\text { et al. (2007)a }\end{array}$ & 18 & 14.5 & 50.0 & - & $\mathrm{PE}+\mathrm{ERP}+\mathrm{CT}+\mathrm{RP}$ & 14 & 1.5 & High & 2.9 & $\mathrm{RCT}$ & 2.073 \\
\hline $\begin{array}{l}\text { Storch, Geffken } \\
\text { et al. (2007)b }\end{array}$ & 18 & 12.0 & 50.0 & - & $\mathrm{PE}+\mathrm{ERP}+\mathrm{CT}+\mathrm{RP}$ & 3 & 7 & High & 2.9 & $\mathrm{RCT}$ & 2.789 \\
\hline $\begin{array}{r}\text { Storch, Merlo } \\
\text { et al. (2008) }\end{array}$ & 85 & 13.6 & 53.3 & - & $\mathrm{PE}+\mathrm{ERP}+\mathrm{CT}+\mathrm{RP}$ & 8.9 & 2.37 & High & 2.9 & One-group & 2.616 \\
\hline $\begin{array}{l}\text { Storch, Murphy } \\
\text { et al. (2006) }\end{array}$ & 7 & 11.1 & 57.1 & 4.6 & $\mathrm{PE}+\mathrm{ERP}+\mathrm{CT}+\mathrm{RP}$ & 3 & 7 & High & 2.0 & One-group & 3.148 \\
\hline $\begin{array}{l}\text { Thienemann } \\
\text { et al. (2001) }\end{array}$ & 18 & 15.2 & 66.7 & 4.9 & $\mathrm{PE}+\mathrm{ERP}+\mathrm{CT}$ & 14 & 2 & Medium & 3.0 & One-group & 1.033 \\
\hline $\begin{array}{l}\text { Turner et al. } \\
\text { (2009) }\end{array}$ & 10 & 15.0 & 80.0 & 8 & $\mathrm{PE}+\mathrm{ERP}+\mathrm{CT}$ & 16 & - & Medium & 2.5 & One-group & 1.477 \\
\hline $\begin{array}{l}\text { Valderhaug } \\
\text { et al. (2007) }\end{array}$ & 24 & 13.3 & 50.0 & - & $\mathrm{PE}+\mathrm{ERP}+\mathrm{CT}+\mathrm{RP}$ & 12 & 1.17 & High & 1.9 & One-group & 4.361 \\
\hline $\begin{array}{l}\text { Waters et al. } \\
\text { (2001) }\end{array}$ & 7 & 11.6 & 60.0 & - & $\mathrm{PE}+\mathrm{ERP}+\mathrm{CT}+\mathrm{RP}$ & 14 & 1.5 & High & 0.7 & One-group & 3.779 \\
\hline $\begin{array}{l}\text { Whiteside \& } \\
\text { Jacobson } \\
\text { (2010) }\end{array}$ & 16 & 13.13 & 56.3 & - & $\mathrm{PE}+\mathrm{ERP}+\mathrm{CT}+\mathrm{RP}$ & 0.7 & 8.5 & High & 2.94 & One-group & 2.241 \\
\hline $\begin{array}{l}\text { Williams et al. } \\
\text { (2010)a }\end{array}$ & 10 & 13.6 & 61.9 & - & $\mathrm{PE}+\mathrm{CT}+\mathrm{BE}$ & 12 & 0.83 & Low & 4.9 & $\mathrm{RCT}$ & 1.552 \\
\hline $\begin{array}{l}\text { Williams et al. } \\
\qquad(2010) \mathrm{b}\end{array}$ & 10 & 13.6 & 61.9 & - & $\begin{array}{l}\text { Inactive control } \\
\text { group }\end{array}$ & - & - & - & 4.9 & $\mathrm{RCT}$ & 0.346 \\
\hline
\end{tabular}

Note: N: sample size in the posttest for each group. Gender: percentage of males in the sample. OCD history: mean of the years suffering the OCD. Treatment techniques: PE (psychoeducation), BF (biofeedback), ERP (exposure with response prevention), CT (cognitive training), RP (relapse prevention), and BE (behavioral experiments). Duration: treatment duration (in weeks). Intensity: treatment intensity (number of hours per week). Quality: design quality (in a $0-6$ points scale). Design: RCT (randomized-controlled trial), two-groups (nonrandomized) design, and one-group design. $d$ : effect size for obsessivecompulsive symptoms. 